\title{
A Review of Lithium-Ion Battery State of Health Estimation and Prediction Methods
}

\author{
Lei Yao ${ }^{1}$, Shiming $X u^{1}$, Aihua Tang ${ }^{2,3, *}$, Fang Zhou ${ }^{1}$, Junjian Hou ${ }^{1}$, Yanqiu Xiao ${ }^{1, *}$ and Zhijun Fu ${ }^{1}$ \\ 1 Henan Engineering Research Center of New Energy Vehicle Lightweight Design and Manufacturing, \\ Zhengzhou University of Light Industry, Zhengzhou 450000, China; yl04410003@126.com (L.Y.); \\ xsm1235@yeah.net (S.X.); xsm1235@163.com (F.Z.); houjunjian@zzuli.edu.cn (J.H.); \\ xsm17629066085@163.com (Z.F.) \\ 2 Vehicle Engineering Institute, Chongqing University of Technology, Chongqing 400054, China \\ 3 Key Laboratory of Advanced Manufacturing Technology for Automobile Parts, Ministry of Education, \\ Chongqing University of Technology, Chongqing 400054, China \\ * Correspondence: aihuatang@cqut.edu.cn (A.T.); 2016008@zzuli.edu.cn (Y.X.)
}

Citation: Yao, L.; Xu, S.; Tang, A.;

Zhou, F.; Hou, J.; Xiao, Y.; Fu, Z. A Review of Lithium-Ion Battery State of Health Estimation and Prediction Methods. World Electr. Veh. J. 2021, 12, 113. https://doi.org/10.3390/ wevj12030113

Academic Editor: Joeri Van Mierlo

Received: 1 July 2021

Accepted: 8 August 2021

Published: 10 August 2021

Publisher's Note: MDPI stays neutral with regard to jurisdictional claims in published maps and institutional affiliations.

Copyright: (c) 2021 by the authors. Licensee MDPI, Basel, Switzerland. This article is an open access article distributed under the terms and conditions of the Creative Commons Attribution (CC BY) license (https:// creativecommons.org/licenses/by/ $4.0 /)$.

\begin{abstract}
Lithium-ion power batteries have been widely used in transportation due to their advantages of long life, high specific power, and energy. However, the safety problems caused by the inaccurate estimation and prediction of battery health state have attracted wide attention in academic circles. In this paper, the degradation mechanism and main definitions of state of health (SOH) were described by summarizing domestic and foreign literatures. The estimation and prediction methods of lithium-ion power battery $\mathrm{SOH}$ were discussed from three aspects: model-based methods, data-driven methods, and fusion technology methods. This review summarizes the advantages and disadvantages of the current mainstream $\mathrm{SOH}$ estimation and prediction methods. This paper believes that more innovative feature parameter extraction methods, multi-algorithm coupling, combined with cloud platform and other technologies will be the development trend of $\mathrm{SOH}$ estimation and prediction in the future, which provides a reference for health state estimation and prediction of lithium-ion power battery.
\end{abstract}

Keywords: lithium-ion power battery; state of health; data-driven methods; fusion technology

\section{Introduction}

Due to the characteristics of long cycle life, high specific energy, specific power, low self-discharge rate, high-temperature range, and the advantages of little pollution to the environment [1], lithium-ion power batteries (from now on referred to as lithium battery) are widely applied in various fields. In the area of transportation, to adapt to people's fast pace of life and rising material demand, more and more countries are investing a lot of financial and material resources into research and developing transportation electrification, thus electric vehicle technology has been widely promoted and applied [2-7]. According to statistics, the inaccurate $\mathrm{SOH}$ estimation and life prediction of lithium batteries are the leading causes of electric vehicle spontaneous combustion accidents [8-10]. How to accurately estimate the lithium battery $\mathrm{SOH}$ has become a research hotspot for many scholars. Because the health status of lithium batteries is difficult to measure, time-varying, and easy to disturb, the high-precision health status estimation and prediction is the core technical challenge that urgently requires solving.

In recent years, many scholars have carried out many review studies on lithium-ion power batteries. Ungurean et al. [11] introduced a new set of indicators to analyze different $\mathrm{SOH}$ estimation and prediction algorithms from the perspective of operational efficiency in the context of embedded application environment. Yang et al. [12] classified SOH estimation methods according to characteristic parameters when defining $\mathrm{SOH}$, and summarized them from two perspectives: short-term and long-term. Li et al. [13] more comprehensively 
reviewed battery health diagnosis and prediction from a data-driven perspective, based on engineering applications and cost-Ungurean effectiveness. Feng et al. [14] performed a detailed analysis of vehicle lithium-ion batteries from the perspective of the microscopic thermal runaway mechanism. Literature [15], from the perspective of macroscopic fault diagnosis of lithium batteries, analyzed its safety evolution mechanism and summarized existing fault diagnosis methods. Tian et al. [16] classified, compared, and predicted the $\mathrm{SOH}$ management system for lithium batteries according to the different extraction methods of health state parameters. Based on the premise of economic feasibility and life cycle of lithium batteries, literature [17] explained the beneficial impact of lithium battery recycling on the ecological environment and summarized the current situation of lithium battery recycling and utilization. Due to the numerous methods and disorganized system for $\mathrm{SOH}$ estimation and prediction at present, the review perspectives of review pieces of literature are also different. Therefore, we summarized the typical methods of different types and analyzed their application characteristics to reference subsequent studies.

In the field of $\mathrm{SOH}$ prediction and estimation of lithium-ion batteries, the classification methods of the existing relevant reviews are usually relatively rough, and the review methods are few. There is room for improvement in the depth of comparison and discussion of standard procedures. Therefore, this paper starts with the definition of lithium battery health state and the decline mechanism, divides the methods of health state estimation and prediction into nine categories in a more detailed way, and compares them with each other. The advantages and disadvantages of each typical method, as well as the application scope, are analyzed. In addition, the development trend of lithium battery health state estimation and prediction methods are proposed in combination with the rules of model building methods and the development of big data and 5G cloud technology. The structure of this paper is as follows: Section 2 analyzes the degradation mechanism of lithium batteries and expounds on the current definition standards of $\mathrm{SOH}$ from the perspective of capacity and internal resistance of lithium batteries. In the third section, combined with the problems and difficulties of current $\mathrm{SOH}$ estimation and prediction of lithium batteries, the existing typical $\mathrm{SOH}$ estimation, and prediction methods are classified and sorted, and the advantages and disadvantages of each technique and the application scope are emphasized. In the fourth section, the existing challenges and future research directions of $\mathrm{SOH}$ estimation and prediction for lithium batteries are presented. Finally, the fifth section summarizes the whole paper.

\section{Lithium-Ion Battery Attenuation Mechanism and SOH Definition}

\subsection{Fading Mechanism of Lithium-Ion Battery}

For today's mainstream vehicle power battery, based on the above analysis, battery capacity decline is an important indicator of status of health, and the main reasons for capacity decline are as follows:

- Phase transition of electrode materials: Taking lithium manganese oxide battery as an example, its capacity decline is mainly caused by manganese-ions' dissolution. When manganese-ions are free to the negative electrode, the solid electrolyte interphase (SEI) membrane will be destroyed. In contrast, the interface membrane's reformation requires the consumption of lithium-ions, resulting in the decrease of available lithiumions. The experiments in the literature [18] have proved this point of view. Through the study on the aging characteristics of lithium-ion batteries, it is found that the aging degree of lithium-ion batteries will deepen with the increase of the charging and discharging times. During the charge and discharge process, the SEI film resistance increases continuously. The battery's impedance characteristic is strengthened, and the ion diffusion coefficient at the electrode decreases, resulting in the rapid reduction of discharge voltage and the rapid attenuation of discharge capacity. This is not the case for some batteries, such as lithium titanate batteries, which may not produce an SEI film during operation. 
- The electrode kinetics performance of recession: Using inductively coupled plasma emission spectrometer specific capacity, impedance characteristics of the electrode and the polarization characteristics were analyzed [19], and found to be the lithium-ion battery charge and discharge cycle, phase change is negative, ohm resistance, SEI film resistances were significantly increased, anode of lithium-ion is embedded in the reaction, resulting in decreased electrode ion storage capacity, and capacity loss, indicating that the battery capacity loss is negative dynamic performance and is the main cause of the recession.

- The decomposition of electrolyte: in the process of charge and discharge, the electrolyte itself has a certain instability, and the reduction reaction will occur with the carboncontaining electrode, and the reduction reaction will consume the electrolyte and its solvent. Mei [20] et al. used separators to observe lithium-ion batteries' internal structure and proposed that the decrease of ionic conductivity would lead to electrolyte decomposition, thus reducing the battery capacity.

- The generation of SEI film: the formation of SEI film is the product of the reduction reaction that occurs after the contact between organic solvent and the anode material. The lithium-ion consumed due to the generation of SEI film will change the capacity balance [21,22]. Meanwhile, the SEI film will cause isolation of the electrode and deactivation, resulting in reduced capacity.

Therefore, $\mathrm{SOH}$ deterioration of lithium-ion battery is affected by many factors such as electrode material phase change, electrode dynamic performance, electrolyte decomposition state, and SEI film formation [23-25]. The basic principle is shown in Figure 1. The reasons, effects and results of the decline of lithium-ion batteries are summarized in Table 1. Quantifying the decline mechanism is helpful to improve $\mathrm{SOH}$ estimation and prediction ability of lithium-ion batteries and help reduce the capacity decay in the use of lithium-ion batteries.

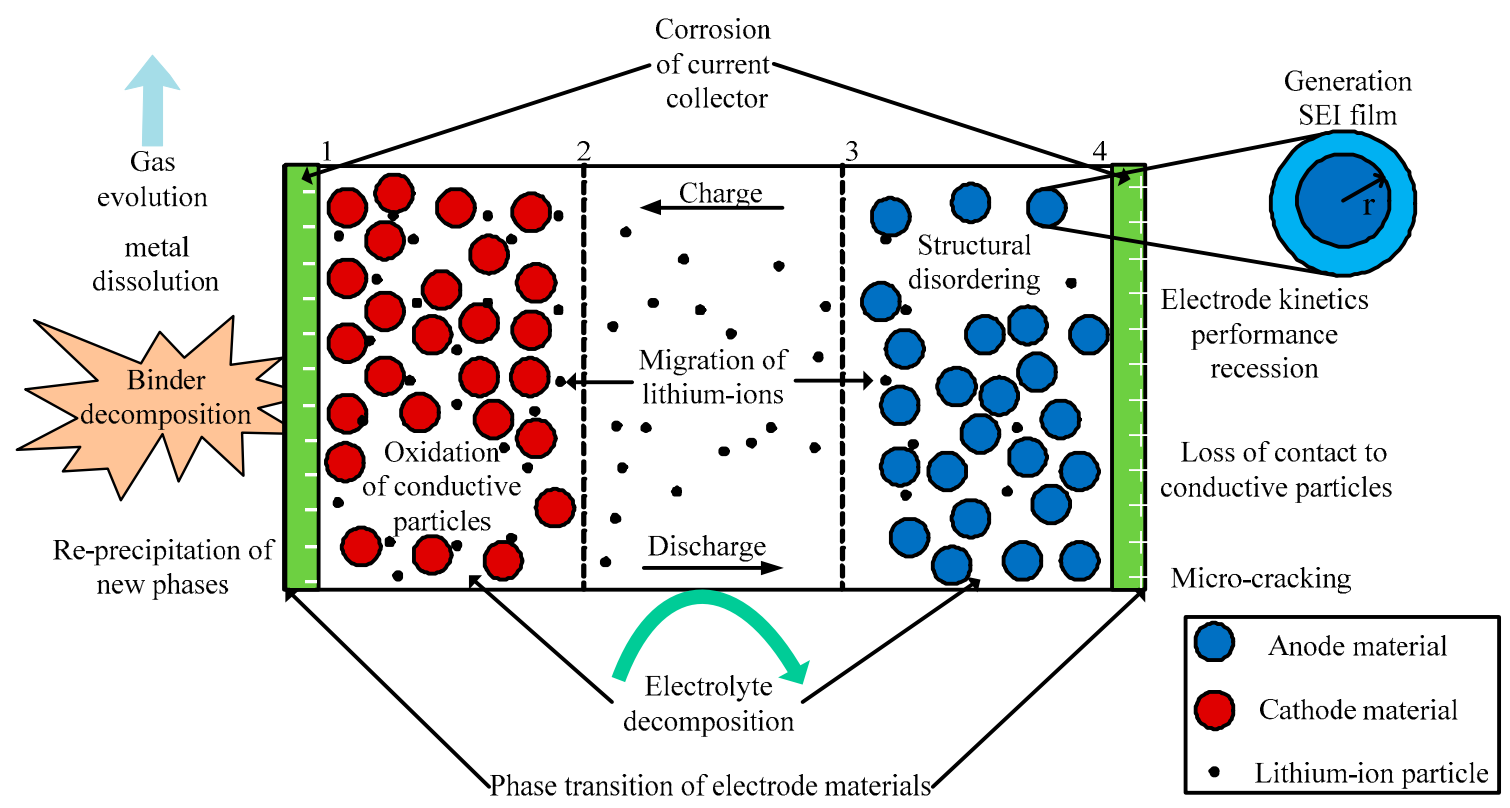

Figure 1. Basic schematic of lithium-ion battery aging. 
Table 1. Causes, effects and results of lithium-ion battery decline.

\begin{tabular}{|c|c|c|c|}
\hline Sequence Number & Recession Reason & Influence & Consequence \\
\hline 1 & $\begin{array}{l}\text { Phase transition of electrode } \\
\text { materials }\end{array}$ & $\begin{array}{l}\text { Crystal distortion, internal } \\
\text { stress changes. }\end{array}$ & The capacity decreases \\
\hline 2 & $\begin{array}{l}\text { The electrode kinetics } \\
\text { performance of recession }\end{array}$ & $\begin{array}{l}\text { The inactivation and } \\
\text { disembedment, reactions were } \\
\text { difficult to carry out. }\end{array}$ & $\begin{array}{c}\text { The internal resistance increases, } \\
\text { the capacity decreases. }\end{array}$ \\
\hline 3 & $\begin{array}{l}\text { The decomposition of } \\
\text { electrolyte }\end{array}$ & $\begin{array}{l}\text { Reduction reaction, gas } \\
\text { overflow. }\end{array}$ & The capacity decreases \\
\hline 4 & The generation of SEI film & $\begin{array}{c}\text { Lithium-ion depletion and } \\
\text { deactivation. }\end{array}$ & $\begin{array}{l}\text { The capacity decreases, power } \\
\text { reduction. }\end{array}$ \\
\hline
\end{tabular}

\subsection{Definition Status of Health of Lithium-Ion Batteries}

With the increase of battery charging and discharging times and the accumulation of sheltering time, the battery health status gradually deteriorates, its power and capacity show varying degrees of attenuation, the battery capacity decreases, and the internal resistance increases. Thus, the capacity and internal resistance are commonly used to define $\mathrm{SOH}$.

\subsubsection{Capacity Definition}

$\mathrm{SOH}$ is one of the important parameters of lithium-ion batteries, which is calibrated according to the change of battery capacity, as follows:

$$
\mathrm{SOH}=\frac{\mathrm{Q}_{\mathrm{m}}}{\mathrm{Q}_{\mathrm{r}}} \times 100 \%
$$

where: $Q_{r}$ - rated capacity and $Q_{m}$ — current maximum available capacity of the battery, which is measured under rated conditions [26-28]. Due to the influence of temperature and measurement current multiplier, $\mathrm{SOH}$ values also vary significantly [29-31].

To ensure the performance requirements of lithium-ion batteries, IEEE standard 1188.1996 clearly states that when the battery $\mathrm{SOH}$ is less than $80 \%$, it indicates that the end of life has been reached and the battery needs to be replaced [32-34].

\subsubsection{Internal Resistance Definition}

$\mathrm{SOH}$ is defined according to the internal resistance of the battery as follows:

$$
\mathrm{SOH}=\frac{\mathrm{R}_{\mathrm{e}}-\mathrm{R}}{\mathrm{R}_{\mathrm{e}}-\mathrm{R}_{\mathrm{n}}} \times 100 \%
$$

where: $\mathrm{R}$-internal resistance under the current state; $\mathrm{R}_{\mathrm{e}}$-internal resistance of the battery when it reaches the end of life; and $R_{n}$-internal resistance of the new battery. Many scholars define battery $\mathrm{SOH}$ by internal resistance or estimate and predict $\mathrm{SOH}$ based on internal resistance of the battery [35-37]. The increase of internal resistance is also an important indicator of battery aging, and it is also one of the reasons for the further decline of battery $\mathrm{SOH}$.

\subsubsection{The Definition of Capacity Contained in the Electrode}

With the use of lithium batteries, lithium ions will move along with the charge transfer. According to the electrochemical reaction mechanism of the electrode, the $\mathrm{SOH}$ of lithium batteries can be evaluated by the concentration of lithium ions in the electrode [38]. In the ideal state, $\mathrm{SOH}$ can be expressed as:

$$
\mathrm{SOH}=\frac{\mathrm{Q}}{\mathrm{Q}_{0}} \times 100 \%
$$


where: $\mathrm{Q}$-nominal capacity and $\mathrm{Q}_{0}$ —smaller lithium concentration after multiple cycles.

\section{Statue of Health Estimation and Prediction of Lithium-Ion Batteries}

Inaccurate $\mathrm{SOH}$ estimation and prediction can easily lead to misjudgment of the battery operating state, affect accurate identification of battery fault state, and increase the risk of the battery system's hidden safety hazard [39-41]. Therefore, the accurate estimation and prediction of lithium battery $\mathrm{SOH}$ is very important in vehicle operation. Currently, the estimation and prediction of lithium battery $\mathrm{SOH}$ mainly face four problems:

- Difficulty in measurement: Lithium-ion battery $\mathrm{SOH}$ is an internal parameter of batteries, which cannot be directly measured by sensor. Only with voltage, current and temperature, and other relevant parameters can it be obtained by integration, approximate processing, and other methods, increasing the difficulty of accurate identification of $\mathrm{SOH}$ parameters.

- Strong time variability: Lithium-ion battery $\mathrm{SOH}$ is not only closely related to environmental stresses such as temperature, current and loading mode, but is also affected by internal multi-parameter coupling such as the current internal ion motion state, the ratio of positive and negative active materials, and the intensity of electrochemical reaction.

- Irreversibility: At present, most of the prediction methods adopt irreversible off-line state data for prediction, which is affected by monomers' differences and has a low repeatability. At the same time, the reliability and timeliness of online identification are poor.

- High nonlinearity: In the actual operation process, the state of health of lithium-ion batteries is cross-coupled by multiple internal and external factors, and its degradation curve is highly nonlinear, which increases the difficulty of accurate identification and reliability of $\mathrm{SOH}$.

Based on the above problems, current research mainly performs systematic research from many aspects, such as accurate model building, system state parameter prediction and data architecture design, etc., which can be divided into three categories: Model-based method, data-driven method, and fusion technology method. The classification structure of $\mathrm{SOH}$ estimation and prediction algorithm is shown in the Figure 2.

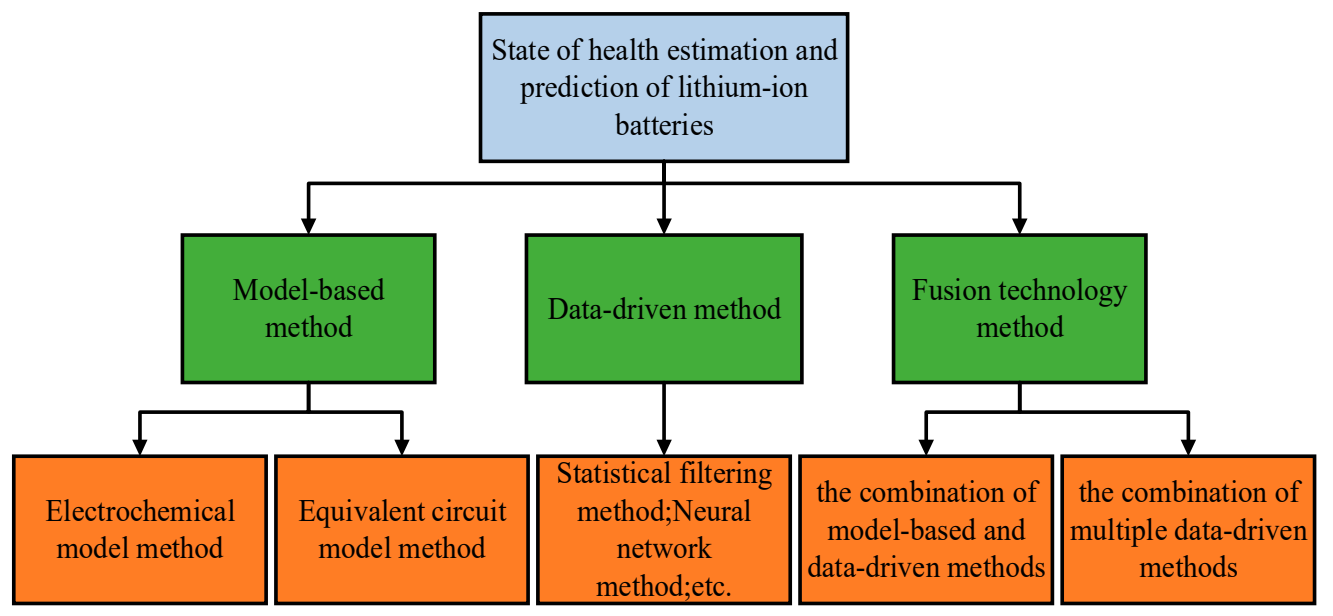

Figure 2. Algorithm classification structure.

\subsection{Model-Based Method}

The model-based method is based on the degradation and the failure mechanism of lithium-ion batteries to realize the estimation and prediction of $\mathrm{SOH}$. The accuracy of the estimation depends on the decay law of the model's key parameters representing the internal aging degree [42-44]. This method is relatively mature, mainly including several forms, such as the electrochemical impedance spectroscopy (EIS) model [45-47], 
the thermoelectric coupling model [48-50], the Thevenin model [51-53], and the shunt of the multi-stage resistor-circuit (RC) model [54-56]. According to the difference between the theory of model construction and the principle of algorithm in state prediction, it can be divided into two categories: electrochemical models and equivalent circuit models.

\subsubsection{Electrochemical Model Method}

The electrochemical model is mainly based on the electrochemical reaction mechanism inside the lithium-ion battery. The porous electrode theory and kinetic knowledge are adopted to establish a physical model by extracting internal parameters representing the battery's dynamic aging and failure process, which can be used for $\mathrm{SOH}$ estimation and prediction [57-59]. Zhang et al. [60] analyzed the impedance characteristics through a pseudo 2-dimensional (P2D) model based on the variation of battery impedance characteristics. They found that the low frequency band's impedance characteristics were consistent with the actual battery impedance characteristics. On this basis, the original model was revised and compared with the EIS model, so that the prediction error was reduced by half compared with the original model. Improved reliability is more suitable for $\mathrm{SOH}$ estimation under actual operating conditions. The authors [61], in the porous electrode based on the theoretical model, from the perspective of macro battery parameters, put forward thinking of battery terminal voltage, load current, and factors such as the polarization impedance electrochemical model, and one-dimensional order reduction based on discrete-time estimation algorithm to achieve the status of the battery, estimate that this method avoids the nonlinear optimization.

The electrochemical model method has a strong theoretical support, which can determine the detailed internal electrochemical reaction process and reaction intensity in the battery's aging process. It can accurately characterize lithium-ions' movement law and the change trend of active substances in positive and negative electrodes at different $\mathrm{SOH}$ locations. However, the lithium-ion battery electrochemistry system is more complex, having many side effects in real time. As the working condition is different, the intensity is different (varies), which describes the aging condition of the model as being relatively complex, having characteristic parameters coupled with each other, leading to poor generality, the method to use single range, dynamic prediction accuracy is poor, and does not favor online real-time $\mathrm{SOH}$ estimation and prediction.

\subsubsection{Equivalent Circuit Model Method}

The equivalent circuit model as a modeling method, is based mainly from the perspective of electrotechnics; the battery as a black box, according to the working system of input-output corresponding relations to the building of electrical components, it is essentially the building of a mathematical model to represent a lithium-ion battery, which has become a circuit model to describe the lithium battery capacity decline characteristics. The equation of state was selected based on Kirchhoff's current equation and Kirchhoff's voltage equation. Combined with known quantities that could be measured, parameters related to $\mathrm{SOH}$ estimation were extrapolated to finally achieve the purpose of estimating $\mathrm{SOH}$ [62-65]. Common equivalent circuit models mainly include: Rint model, Thevenin model, partnership for a new generation of vehicles (PNGV) model, and multi-stage RC model. The Rint model is shown in Figure 3a. This model linearizes the battery characteristics and is easy to operate. However, due to the over-idealization of modeling, the error is large. Wei [66] et al., considered the strong capacitance characteristics of the battery, added a parallel module of resistor and capacitor, and selected the first-order Thevenin model, as shown in Figure 3b. The grey neural network was introduced for offline training, and the health index (HI) was taken as the input parameter, battery capacity degradation was taken as the output parameter of the grey neural network model, and finally, battery $\mathrm{SOH}$ was estimated by online construction of battery HI. Panchal [67] used driving cycle data from the actual operation of the electric vehicle. These data include the battery application environment of highways and cities at different temperatures. The Thevenin battery 
model and the empirical degradation model are constructed in MATLAB, which accurately estimates the degree of capacity decline and predicts future battery life.

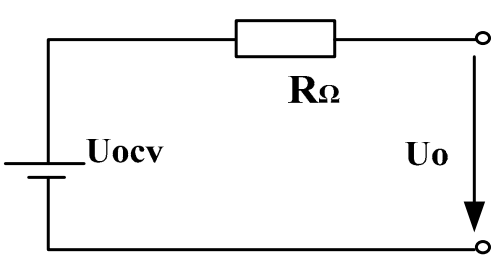

(a)

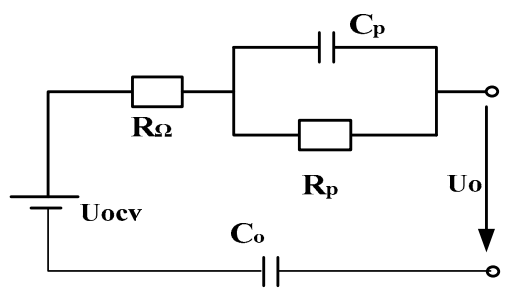

(c)

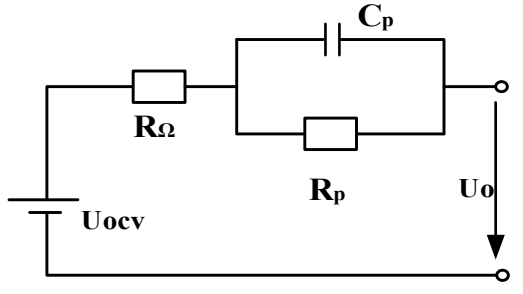

(b)

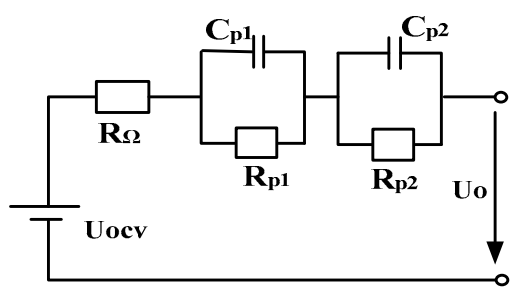

(d)

Figure 3. Schematic diagram of equivalent circuit mode: (a) The Rint model; (b) The Thevenin model; (c) The PNGV model; (d) The RC model.

To further highlight the capacitive characteristics of the battery, Liu et al. [68] combined the PNGV model and Kalman filtering method to calculate the model parameters under different states of charge by charging and discharging batteries, measured the open-circuit voltage and state of charge of lithium batteries, and compared them with the internal resistance correction method. It is proved that PNGV model can accurately describe characteristics of lithium batteries in the charging and discharging processes. The PNGV model is shown in Figure 3c. Due to the high nonlinear characteristics, the battery working characteristics, the multistage RC model was widely used, as shown in Figure 3d; in [69], the authors make a comparison of different order RC equivalent circuit models; a second order RC model, for example, is a first order RC model with a large amount of calculation. However, its accuracy has improved greatly, which indicates that the second order RC network model for dynamic state estimation has better effect. On the basis of the Thevenin model principle, this model mainly considers the ion migration and embedment process during the battery cycle. Moreover, the impedance spectrum curve showed irregular semicircle features. The accuracy and reliability of the model prediction can be improved by adding more RC series modules while the increased number of state parameters make the identification process difficult. Thus, the accuracy and robustness of models are enhanced, but applicability in real-time is reduced [70].

Fractional-order models are also used in state estimation and life prediction. Wang [71] proposed a fractional modeling method for lithium-ion batteries. Firstly, the model structure of the lithium-ion battery is determined by testing. Secondly, a temperature compensation fractional-order model is established. Finally, a globally optimized time-domain parameter identification method is introduced. The results show that the new fractionalorder model has high accuracy.

An equivalent circuit model of $\mathrm{SOH}$ estimation and prediction method with strong engineering practicality, compared with the electrochemical model, less parameters, strong timeliness, but the approximate calculation may ignore some weak influence on lithium-ion battery $\mathrm{SOH}$ attenuation change, cannot consider that the function of the complex external stress change is complete, with the improvement of the development of technology and precision requirement, which will lead to the equivalent circuit model of limited battery 
$\mathrm{SOH}$ estimation and prediction accuracy. The advantage and disadvantages of different lithium-ion battery models are summarized in Table 2.

Table 2. Advantage and disadvantages of lithium-ion battery models.

\begin{tabular}{ccc}
\hline Method & Advantage & Disadvantage \\
\hline $\begin{array}{c}\text { Electrochemical model } \\
\text { method }\end{array}$ & $\begin{array}{c}\text { High precision, the theory of } \\
\text { aging is well supported, the } \\
\text { movement law of ions and the } \\
\text { change trend of active } \\
\text { substances are described. }\end{array}$ & $\begin{array}{c}\text { Model complexity, more } \\
\text { parameters, online estimation } \\
\text { and prediction ability is weak. }\end{array}$ \\
\hline $\begin{array}{c}\text { Equivalent circuit model } \\
\text { method }\end{array}$ & $\begin{array}{c}\text { Model simplicity, methods } \\
\text { mature, easy to operate, high } \\
\text { engineering application value. }\end{array}$ & $\begin{array}{c}\text { With the development of } \\
\text { technology, the accuracy } \\
\text { cannot meet the requirements. }\end{array}$ \\
\hline
\end{tabular}

\subsection{Data-Driven Method}

The accuracy of model-based methods usually depends on the complexity of the model and the accuracy of parameter identification. Combined with the characteristics of difficult measurement of $\mathrm{SOH}$ and strong time variation, this method's anti-interference ability is weak in practical application, and the reliability and high levels of accuracy are difficult to reach [72-74]. With data mining and big data analysis technology development, the data-driven method has become a hot topic for more researchers at this stage [75-77]. The data-driven method does not need to consider the complex electrochemical changes and the fluctuations of related active substances inside the lithium-ion battery. By extracting the characteristic values of parameters measured directly or indirectly and combined with the data mining algorithm, the relationship between characteristic parameters and state of health is established from the data's overall level [78-80]. The data of battery aging is critical to building the corresponding model, and it is costly to collect these data. For example, NASA, CALCE, MIT, HKUST, Oxford, and other databases have provided us with a large number of data on the impact of different environmental stresses on battery life, which has provided significant help for the subsequent development of scientific research.

Due to the lithium-ion battery systems usually consisting of a large number of monomer battery in series/parallel mode, characteristic parameters do not only reflect different monomer battery working environment effects on the research object and interference, but can also characterize the monomer battery charged state and aging between comparison with the model law, it is not sensitive to some characteristic data, good antiinterference ability, strong universality, and high dynamic accuracy. According to the difference in data mining methods, the main data-driven methods at the present stage are divided into four categories: statistical filtering method, neural network method, vector machine method, and statistical data method.

\subsubsection{Statistical Filtering Method}

Statistical filtering is a method to extract and reproduce effective signals and waveforms from data containing many noise signals. Commonly used statistical filtering methods are mainly divided into Kalman filtering (KF) and particle filtering (PF).

$\mathrm{KF}$ is a level-by-level recursive linear data processing algorithm that automatically calculates and determines the best weighting factor. Simultaneously, the weighted factor can be automatically adjusted to keep the result in the best state all the time, thus having a strong target following ability [81-83]. Due to the highly nonlinear characteristics of lithium-ion batteries during operation, it is difficult for a single KF algorithm to meet the system's requirements [84], which limits the application of KF in the actual operation scenarios of lithium-ion batteries. In order to meet the requirements of high accuracy and reliability of $\mathrm{SOH}$ estimation and prediction for lithium-ion batteries, several improved KF algorithms such as unscented Kalman filtering (UKF) [85] and extended Kalman filter (EKF) [86] have been proposed successfully. A double extended Kalman filter (DEKF) joint 
estimation algorithm combined with the equivalent circuit model was proposed by [87], which is applicable for lithium-ion battery application scenarios by comparison with a single KF. Furthermore, the proposed algorithm has strong robustness.

Based on the Bayesian estimation principle and Monte Carlo method, PF uses particle sets to represent the probability density function on any state spatial model. It is an algorithm to obtain the system state's minimum variance estimation based on the sample mean [88-90]. Due to its nonparametric characteristics, PF does not need to meet the Gaussian distribution when processing nonlinear data filtering problems, and can provide the probabilistic expression form of prediction results. Compared with the KF algorithm, PF has better modeling ability in nonlinear environments. Wang [91] et al. proposed a statespace model based on PF. They introduced optimization parameters of improved Kalman filtering, and the accuracy of prediction results was significantly improved. However, it requires a large amount of calculation. In the case of battery experiment data [92], PF was applied to an empirical model of power decline to predict the life endpoints of each phase of the battery, and the prediction results were verified by using power attenuation data. The results showed that the accuracy of $\mathrm{SOH}$ prediction was continuously improved with the increase in the number of samples. However, with the increase of the environment's complexity, a large number of sample parameters are needed to make the PF prediction results closer to the posterior probability density, which greatly increases the complexity and amount of calculation by the algorithm, resulting in poor timeliness of the online prediction algorithm.

\subsubsection{Neural Network Method}

The neural network method includes: artificial neural network (ANN), convolutional neural network (CNN), and back propagation neural network (BP).

As a prediction method based on nonlinear data, ANN comprises many neurons according to certain rules, which has the characteristics of simple structure and strong learning ability. ANN can approach any nonlinear mapping by increasing the number of hidden layers and neurons [93-95]. There are many kinds of improved algorithms widely used in the estimation and prediction of lithium battery $\mathrm{SOH}$ and state of charge (SOC) and other nonlinear data analysis fields [96]. ANN has a strong nonlinear selflearning ability. Many data samples are used to train and adjust the connection weights and thresholds of its contained neurons, to build an accurate estimation and prediction model. Current, voltage and battery temperatures were collected [97] from constant current constant voltage (CC-CV) charging experiment under 400 cycles. These data are employed to train battery models and predict the battery $\mathrm{SOH}$. The experimental results showed that the error between the extrapolated prediction curve and that measured is less than $1 \%$. The proposed algorithm in this paper greatly improved accuracy and did not need the past $\mathrm{SOH}, \mathrm{SOC}, \mathrm{OCV}$ curves, and other information, which indicates that it has strong applicability. Sarmah [98] et al. put forward combining the experimental testing and numerical processing, the method of attenuation as equivalent variable parameters, the capacity of lithium-ion battery power to study the electrochemical coupling behavior, set up artificial neural network structure model, and used the linear regression algorithm to verify this network model, indicating that battery internal stress characteristics have a strong linear $\mathrm{SOH}$ relationship. Bonfitto [99] took an innovative approach to model and propose a different neural network prediction method combining the fusion estimation of SOH and SOC. The author believed that the SOH estimation depended on the SOC behavior in the recursive closed loop. Hence, the $\mathrm{SOH}$ estimation combined with the SOC prediction results greatly improved the accuracy of the estimation results. The authors of [100], directly adopted 10 groups of real vehicle road test data, and selected current, voltage, temperature, $\mathrm{SOC}$ and $\mathrm{SOH}$ parameters as the characteristic parameters of the neural network at the same time to predict the remaining service life, which improved the credibility of the real-time prediction ability under real vehicle operation. 
The principle of ANN is shown in Figure 4. In the Figure, $b_{1}-b_{5}$ are the thresholds of the hidden layer, $c_{1}-c_{3}$ are the thresholds of output layer, $W_{1}(1-5)$ and $W_{2}(1-3)$ are input and output weights. After a series of training and verification, it output the estimated value of $\mathrm{SOH}$. The improved algorithm of the artificial neural network method is relatively mature, has higher computing accuracy, but has a fitting, and the network structure has difficulty determining the fault; at the same time it does not have uncertainty expression forecast ability, the amount of data on experimental training demand is higher, and when the sample data is small, the approximate method of adaptability is poor.

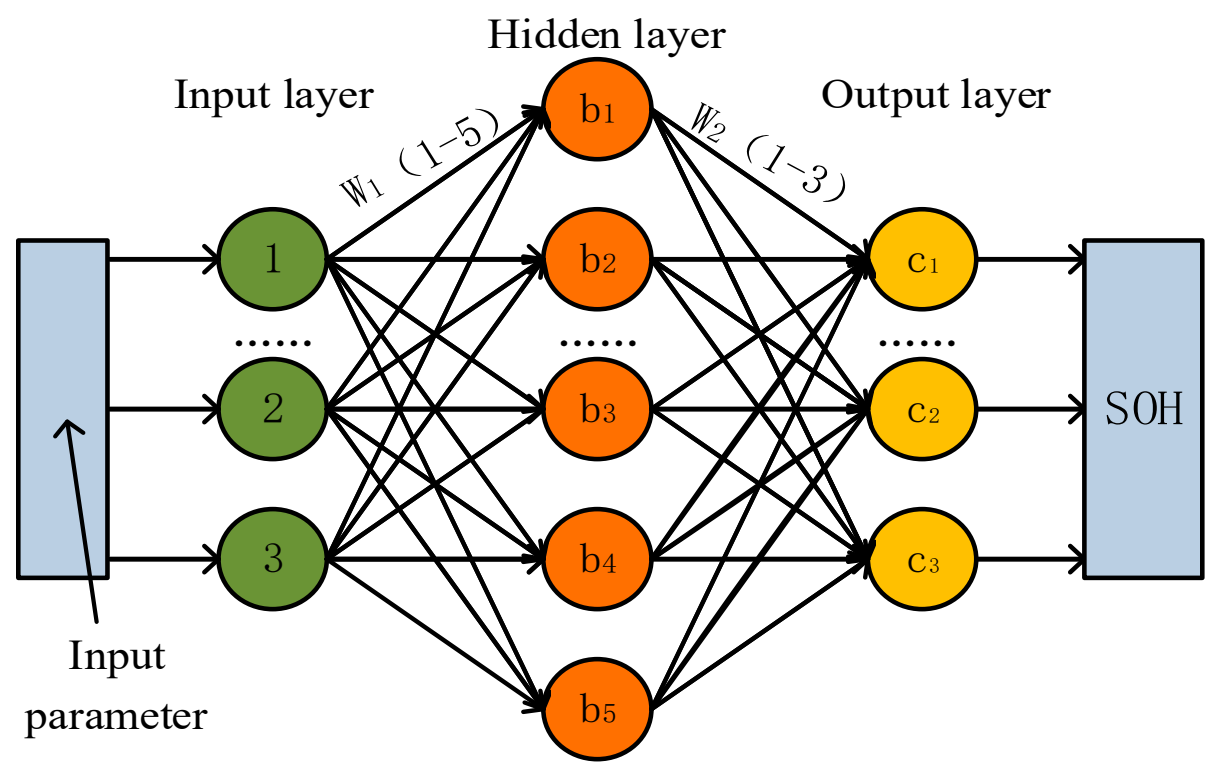

Figure 4. Typical artificial neural network structure.

\subsubsection{Deep Learning Method}

The deep learning (DL) algorithm is derived from the research on the neural network by scholars in recent years [101-103]. The difference between DL and atypical neural networks mainly lies in there being more layers of hidden layer nodes. The deep learning algorithm is a branch of the neural network, and the basic structure of deep learning algorithm is the deep neural network. Deep neural networks, as an algorithm structure, include convolutional neural networks (CNN, Atlanta, GA, USA), recurrent neural networks, and other network structures, and are neural networks with many parameters and layers. With the arrival of big data and 5G cloud computing, the shortcoming of algorithm complexity can be made up for and alleviated by more powerful computing power. More complex deep learning algorithms can be applied in $\mathrm{SOH}$ estimation and life prediction of lithium batteries [104].

As one of the typical algorithm models of deep learning, the CNN stacks the singlelayer convolutional neural network several times. By processing the multi-layer hidden layers, layer by layer, the output of the former layer is used as the input of the last layer. This simple model can be used to complete the task of target learning and significantly reduce the accuracy errors of the calculation results [105]. The disadvantages are also evident, which mainly focus on the need for a large number of training samples and the complexity of the algorithm, which requires the high computing ability of the system. Fan [106] took an innovative approach to model; a hybrid algorithm by using gate-recursive element convolutional neural network (GRU-CNN) was proposed to analyze and study the charging voltage curves of lithium batteries. The measured data, such as voltage, current, and temperature, are used to estimate $\mathrm{SOH}$ online. It provides a novel method for $\mathrm{SOH}$ estimation and life prediction.

Recurrent neural networks (RNN) adopt feedback, which returns output parameters to input and transmits information back to the network to complete a cycle. Therefore, the 
network model can remember historical data and apply them to the prediction. However, when the effective information interval is long, the reverse propagation of the RNN network will produce the phenomenon of gradient disappearance or explosion. To improve the model's performance, researchers modified the original neurons and created a more complex classic structural. A long short-term memory (LSTM) network was proposed to solve this problem. The LSTM algorithm belongs to a variant of RNN as a time series analysis method. Due to its excellent performance, it is used in the SOH estimation and prediction of lithium-ion batteries. For example, in literature [107,108], the LSTM algorithm is adopted to establish a performance degradation model of lithium-ion batteries, and the health degradation degree and remaining service life of the batteries are accurately predicted and estimated through calculation.

At the same time, because LSTM can apply historical data to the prediction, historical data can also improve the model prediction accuracy. Tan [109] adopted long and shortterm memory networks to establish the battery SOH decline model. Based on the transfer learning method, the estimation accuracy of the model for different batteries under different conditions and batches was improved. To further improve the prediction accuracy of the model, the measured historical data and the online measured operational data were utilized as input parameters.

\subsubsection{Vector Machine Method}

The support vector machine (SVM), as a nonlinear data analysis method, can not only provide relatively accurate estimation and prediction results in the case of fewer data samples, but also overcomes the shortcoming that the neural network model easily falls into the optimal local extremum. Fewer unknown parameters and high sparsity characterize the method. Minimizing its structural risk can improve the convergence speed and machine learning ability, thus realizing more accurate $\mathrm{SOH}$ estimation and prediction [110-112]. Because $\mathrm{SOH}$ is strongly influenced by environment and load conditions, Nuhic et al. [113] used the payload data as model training values under different working conditions and put forward some innovation for the SVM algorithm and SVM regression algorithm for the pattern of $\mathrm{SOH}$ accuracy comparison. The results showed that SVM for the probability density function of the prediction ability, the state identification, and SOH prediction, has excellent applicability. Meanwhile, the accuracy of the algorithm is significantly improved. In order to overcome data redundancy, improving the precision of the algorithm budget, an improved support vector machine algorithm based on principal component analysis (PCA) was proposed [114] to optimize the extracted data set, eliminate noise bad points and redundancy, and use a particle swarm optimization algorithm to carry out global optimization of the support vector regression machine, which further improves the prediction accuracy and calculation speed of the model. This method can fuse multiple performance degradation parameters that reflect the health state of lithium-ion batteries, which can fully retain the relevant information of battery performance degradation and remove redundancy. Widodo [115], and others, from the overall state of the system, the discharge voltage sample entropy as characteristic parameter, using the SVM and the relevance vector machine (RVM), respectively, compare the two different algorithms; experiments show the phenomenon that SVM is easily fitted, thus, the generalization prediction ability is weak.

In contrast, the RVM prediction results showed strong adaptability and robustness, and that RVM compared with SVM has more accurate SOH prediction and estimation ability. Therefore, although SVM is simple in operation and high in accuracy, it is sensitive to determining penalty factor and kernel function parameters. Meanwhile, its adaptability to sparse data is limited, and it is prone to overfitting.

The relevance vector machine is an improved learning machine based on sparse Bayesian theory. Compared with the support vector machine, the algorithm reduces the dependence on kernel function and penalty factor selection. It can achieve flexible control of overfitting and underfitting processes by adjusting parameters and the computation is 
simplified. Studies have shown that RVM can reasonably estimate and predict the current $\mathrm{SOH}$ state of the battery with probability characteristics and present the prediction results in the form of probability [116-118]. At present, there are many relevant literatures on the evaluation and prediction of lithium-ion battery SOH using RVM algorithm [119-123]. Based on capacity prediction to evaluate the remaining service life of lithium batteries [124] proposed a method for $\mathrm{SOH}$ prediction of lithium batteries. In this method, the correlation vector machine was combined with the three-parameter capacity degradation model. RVM was used to find the representative eigenvectors and the predicted values of the correlation vectors. The capacity degradation model and the extrapolation model were established to extrapolate to the failure threshold to estimate the battery $\mathrm{SOH}$. The model accuracy is greatly improved. The prediction results and corresponding confidence intervals of the model were given. A prediction method of residual service life of RVM lithium-ion batteries based on dynamic grey correlation was proposed by [125]. The prediction results of the discrete grey model were used as the input parameters of RVM regression prediction, and the model parameters were dynamically updated according to different operation results. The results showed that this method improved the long-term prediction ability of SVM. Zhang [126] et al. proposed a prediction method of battery SOH based on an optimized RVM model for the online application of the RVM model. Compared with the traditional RVM, it reduced the amount of data of online training samples. It improved parameter identification efficiency, providing a new idea for embedded calculation of battery $\mathrm{SOH}$ prediction.

With the advantages of less parameter identification, high sparsity, and arbitrary kernel function, RVM can accurately determine the uncertainty of results in the form of probability. However, when the collected data are too sparse, it can easily lead to low stability and poor immediate repeatability of the results obtained directly by the RVM algorithm. Meanwhile, the accuracy of long-term trend estimation and prediction still need to be further studied.

\subsubsection{Statistical Data Method}

The degradation of lithium-ion battery $\mathrm{SOH}$ is a random process, and the next health state can be inferred according to the statistical data of certain regularity. Statistical data methods usually include the Wiener process (WP) and Gaussian process regression (GPR).

WP is a mathematical model of the Brownian motion process. It is a kind of independent increment process and random movement of Brownian motion is a typical, prediction model based on WP; after proper adjustment, parameters can be used in lithium-ion batteries' SOH estimation and prediction [127-129]. Zhai Q [130] et al. improved a Li-ion battery life prediction method based on an adaptive Wiener process. Based on the traditional Wiener model, a model estimation method based on maximum probability was developed, which used Brownian motion to carry out the adaptive drift and improved the model prediction ability to ensure flexibility. Xu et al. [131] divided the degradation cycle of lithium batteries into three stages: the degradation process of eliminating the relaxation effect; the capacity regeneration process; and the degradation process of regenerated capacity. A new method of SOH estimation based on WP was established based on the degradation model and regenerative capacity model after eliminating the relaxation effect.

GPR is a flexible non-parametric model based on the Bayesian framework. Because it can predict any nonlinear or linear system's behavior characteristics, this algorithm is often used for state prediction of $\mathrm{SOH}$ [132-134]. The process is shown in Figure 5, including:

1. Confirm the function kernel function form;

2. Set the initial value of the super parameter;

3. A prior model is established in the form of probability distribution;

4. The training samples were input into the a prior model for training, and the optimal hyperparameters were obtained to obtain the regression prediction model;

5. Using the input regression prediction model of test samples for prediction; 
6. Output the prediction results, and give the mean and variance of the prediction results with the ability to express uncertainty.

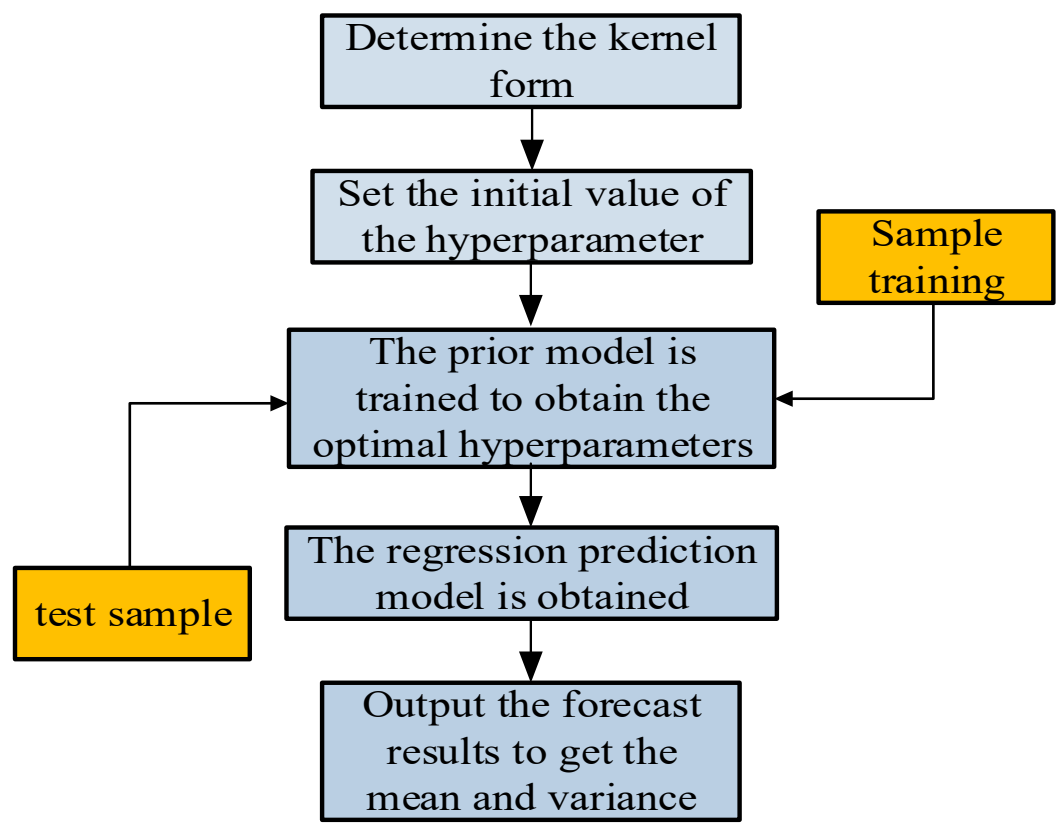

Figure 5. Gaussian process regression flow chart.

In reference [135], discharge current, discharge cutoff voltage, initial capacity, final capacity, and other data are used as input parameters for Gaussian process regression. By comparing with the support vector machine, experiments show that Gaussian process regression has the advantages of small error and high precision. To improve the model's prediction accuracy, Richardson [136] et al. selected different kernel functions for combinatorial optimization. They proposed the calculation method of compound kernel functions, which greatly improved the model's prediction accuracy. Liu [137] et al. used various methods, such as exponential square and periodic square covariance, to optimize the identification results of hyperparameters to achieve the purpose of improving state prediction. Therefore, GPR, compared with the ANN and SVM, ably gives the predicted value of the model and the corresponding confidence interval, which can be estimated according to prior knowledge, to realize the state prediction capability of the expression of uncertainty results. However, the large amount of calculation and super parameter is relatively complex, resulting in a weak ability to apply online. The classification of the data-driven method is shown in Figure 6.

\subsection{Fusion Technology Method}

In recent years, with the deepening of research on $\mathrm{SOH}$ estimation and prediction of lithium-ion batteries, more and more scholars have found that the model-based method: the principle is simple and easy to understand, easy to operate, but its reliability is sensitive to the accuracy of model construction and parameter identification; the data-driven method has strong robustness and strong anti-interference resistance to parameter fluctuation, but it has certain requirements to experimental data. Therefore, many researchers adopt the fusion technology method, which is to establish a hybrid model to estimate and predict the $\mathrm{SOH}$ of lithium-ion battery by superposition of a variety of methods or algorithms, to improve the modeling accuracy and make up for the shortcomings of the single method, so that the algorithm is more suitable for actual operating conditions. 


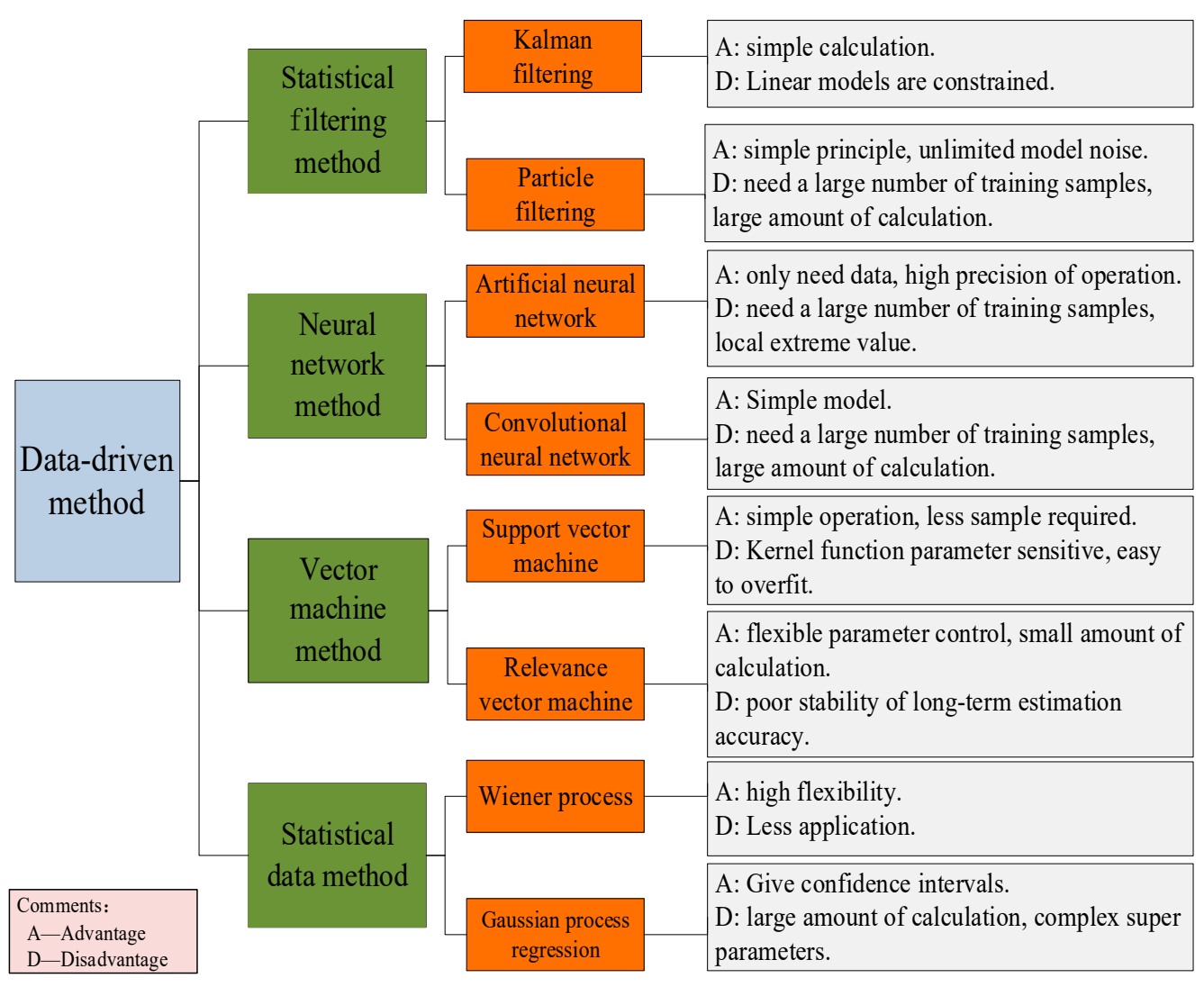

Figure 6. Summary of Data-driven methods.

Fusion technology methods mainly include two categories: the combination of modelbased and data-driven methods [138-140]; and the combination of multiple data-driven methods [141-143].

Based on the combination of the model methods and the data-driven methods, and the complementarity of the two methods, the model analysis was carried out for the characteristic problems such as difficult to measure and nonlinear change of the health state decline of lithium-ion batteries. In reference [144], Li et al. established a fractional order equivalent circuit model of a lithium-ion battery based on second-order RC model. They adopted a particle swarm optimization algorithm and recursive least square method to identify model parameters coupled offline and online. The results show that this method has high reliability and robustness. A double filter combining standard Kalman filter and infinite Kalman filter was adopted by [145] to estimate lithium battery SOH with an SVM algorithm. The periodic aging experiment proved that this method has high accuracy and stability, it is also suitable for SOH estimation of various batteries. Tang [146] used the ICA curve and Kalman filter to establish the $\mathrm{SOH}$ estimation model, and the concepts of regional capacity and regional voltage were innovatively introduced. By mining a large number of experimental data and corresponding regional capacity, batteries accurately estimated $\mathrm{SOH}$. The model did not require SOC and battery impedance data, and the estimation error was less than $2.5 \%$. Chang [147] et al. combined a particle filtering algorithm and correlation vector mechanism to determine an $\mathrm{SOH}$ prediction scheme with the ability to express uncertainty, and through the comparison of four types of experiments, proved that the fusion algorithm could not only guarantee the accuracy of the prediction data, but could also provide accurate evaluation of the uncertainty of the prediction.

The combination of multiple data-driven methods, according to the characteristics of different algorithms, through specific fusion methods led to improved estimation and prediction performance. Hong [148] et al. proposed a fusion SOH estimation method for lithium-ion batteries based on capacity increment analysis and a weighted Kalman 
filtering algorithm, which analyzed the capacity increment of charge and discharge data, extracted health factors, and built a Gaussian nonlinear feature correlation mapping model. Compared with the ordinary Kalman filtering method, it has better prediction accuracy. The fully integrated adaptive empirical mode decomposition method of noise adopted by [149], uses the auto-regressive integral moving average model for data processing, and finally inputs the nonlinear prediction model established by the least square support vector machine (LSVM). Compared with the single SVM algorithm, its prediction ability for nonlinear data is improved.

Ensemble learning (EL) is a combination of multiple data-driven methods, which combines multiple individual learners to achieve the purpose of estimation and prediction [150-152]. According to the integration algorithm between individual learners, it can be divided into two categories:

- Serial integration algorithm with correlation among individual learners. The adaptive boosting algorithm (AdaBoost) can be individual learning series combined into a strong learning, is the typical representation of the serial integration algorithm, Ma et al. [153], using AdaBoost and the stacking algorithm on multiple SVRs merged into two models, established a lithium battery $\mathrm{SOH}$ prediction based on double predictor estimation method, using three kinds of lithium-ion battery the data set was tested. The advantage of AdaBoost is that there are almost no parameters to adjust, and you do not have to worry about overfitting. However, it is sensitive to noise and cannot guarantee the global optimal solution.

- Parallel integration algorithm with no correlation between individual learners. Typical representative is random forests (RF), Li and others [154], measure voltage, current, time of the original signal directly input RF SOH prediction algorithm model, without any pretreatment, and verified by different aging statuses of lithium-ion batteries, and the results show that this algorithm returns low cost, high precision, and root mean square error less than $1.3 \%$. Chen et al. [155] compared the RF, SVM, and least squares support vector machine (LSSVM) estimation ability for lithium-ion battery $\mathrm{SOH}$ and concluded that RF was superior to the other two algorithms. The advantages of RF are: high accuracy can be achieved without a large number of parameters; it works for both classification and regression; again, you do not have to worry about over-fitting; no feature selection is required; and several features can be randomly selected for training each time, but the disadvantage is that compared with other algorithms, the operation time is longer.

Often, advantages and disadvantages of the traditional single algorithm, in prediction ability, are not obvious. After the improvement of the fusion algorithm, the prediction accuracy of the traditional algorithm is improved. However, the fusion method generally has high algorithm complexity, the algorithm compatibility remains to be proven.

\section{Challenges and Prospects}

At present, lithium-ion battery $\mathrm{SOH}$ estimation and prediction has made certain progress. However, in the actual vehicle operation condition or other use in the real environment, the timeliness and accuracy of the algorithm prediction result is today still, the two major challenges facing research based on the traditional forecast model; putting forward the $\mathrm{SOH}$ estimation and forecasting the development trend of lithium batteries, mainly relies on the following three aspects:

- Feature parameter extraction of micro/macro coupling mechanism. Under different battery health conditions, parameters such as voltage, current, resistance, and temperature are often used to characterize the degree of battery aging. In other words, the battery is regarded as a black box, and only the relationship between macroscopic inputs and inputs is considered. However, with the deepening of the theoretical research, the macro characterization of the reaction intensity in the battery will become the core of research because it can more reasonably and efficiently determine the battery's health state. 
- Application of multi-algorithm cross fusion technology. Batteries in actual operation are always affected by temperature, loading mode, and the influence of other factors such as coupling interference. Their internal structure is complex, as the charged state and aging properties are different, characterization of parameters are not the same, so a single algorithm can only meet the prediction of the battery's current specific condition, or characteristic at a certain stage. Many algorithms' cross fusion technology can play to each algorithm's advantage, further improving the estimation and prediction accuracy.

- Implementation of new 5G and cloud platform technologies. Using 5G communication technology and the development of cloud platform technology, enables breaking through the limitation of the calculation processing intensity, use of the technology, such as downloading via mobile communication interface, the transmission of online processing results to the battery management system, improving the system of state parameter identification and calculation of strength, and the ability to apply online algorithm.

\section{Conclusions}

To sum up, this article summarizes the development status of lithium-ion battery $\mathrm{SOH}$ estimation and prediction methods, respectively. Furthermore, this paper expounds the definition of methods of lithium-ion battery state of health, recession, and forecast mechanisms. In view of the four problems mentioned for $\mathrm{SOH}$ estimation and prediction faced in this paper, such as difficult measurement, strong time variability, irreversibility, and high nonlinearity, with emphasis on analysis and comparison of three kinds of lithiumion batteries' state of health merits and demerits of the estimation and prediction methods. Although the model-based methods can better reflect the variation law of internal battery decay, most models are complex, with many parameters, weak online estimation, and prediction ability. With the improvement and development of industrial technology, it is difficult to meet the accuracy of future practical application requirements. Data-driven law is based on a large amount of data. Although it has high precision and functional application ability, it has some problems, such as over-dependence on data, a large amount of calculation, and local extreme values. Therefore, the future trend will be in the form of multi-algorithm coupling, and the selection of state parameters will be further innovated.

Author Contributions: L.Y. contribution establishment of the novel approach and discussion on challenges for battery diagnosis; S.X. reviewed the ageing mechanism of Li-ion batteries as well as diagnosis methods; A.T. improved the overall structure of the paper and edited the paper; J.H. and Y.X. provided overall guidance for the paper. Furthermore, F.Z. and Z.F. provided classic and newest research in related fields. All authors have read and agreed to the published version of the manuscript.

Funding: This research was funded by the National Natural Science Foundation of China, grant number: 62073298; the Department of Science and Technology of HeNan Province, grant numbers: 212102210008 and 212102210237; the Zhengzhou Science and Technology Bureau, grant number: 2020CXZX0046; and the Scientific Research Foundation of Chongqing University of Technology, grant number: 2021ZDZ004.

Institutional Review Board Statement: Not applicable.

Informed Consent Statement: Not applicable.

Data Availability Statement: Not applicable.

Acknowledgments: The authors are grateful to the National Natural Science Foundation of China (No. 62073298), the Department of Science and Technology of Henan Province (No. 212102210008 and 212102210237), the Zhengzhou Science and Technology Bureau (No. 2020CXZX0046) and the Scientific Research Foundation of Chongqing University of Technology.

Conflicts of Interest: The authors declare no conflict of interest. 


\section{Nomenclature}

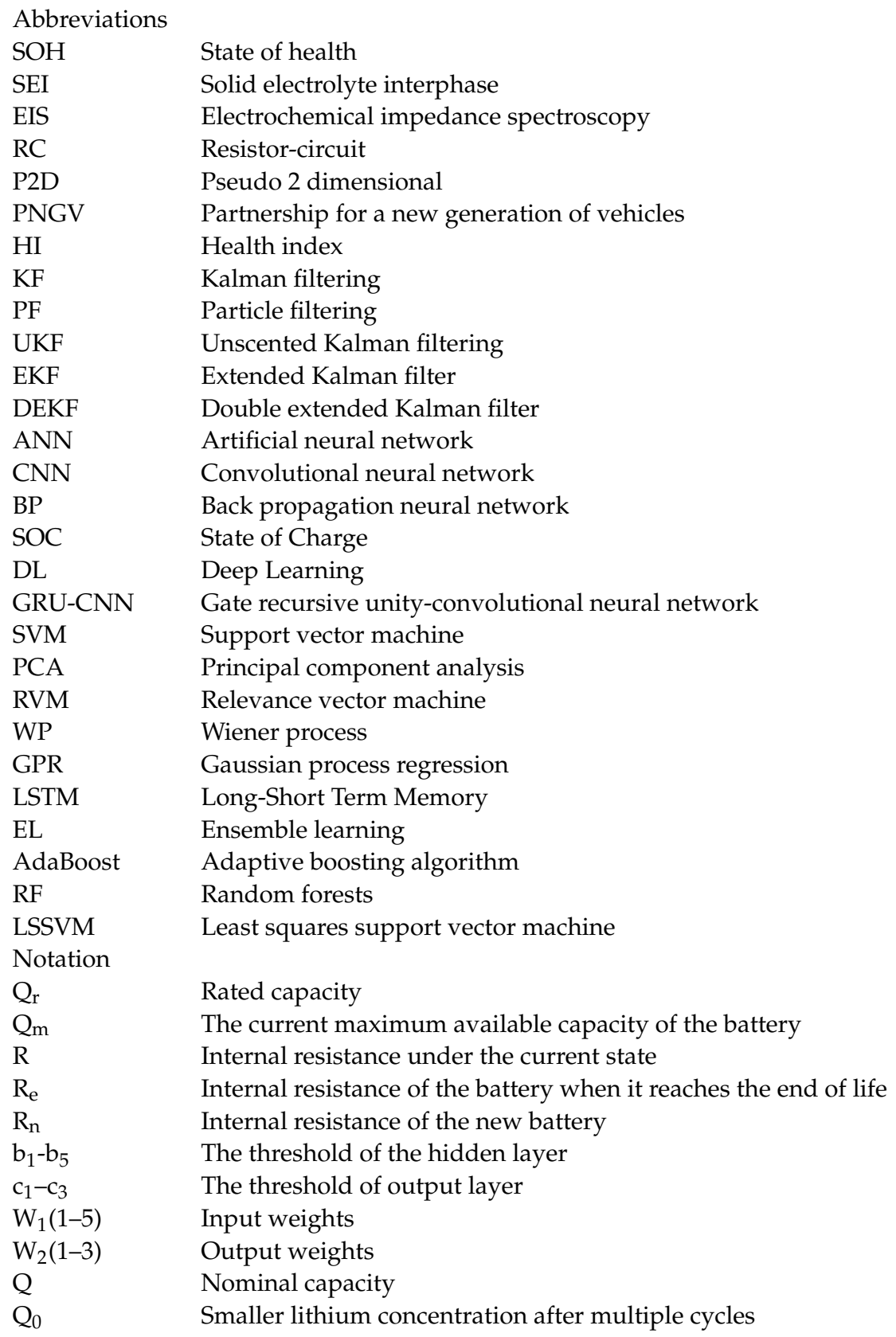

\section{References}

1. Yao, L.; Wang, Z. Research on the charging mode of lithium ion power battery. J. Automot. Eng. 2015, 37, 72-77.

2. Berecibar, M.; Gandiaga, I.; Villarreal, I.; Omar, N.; Mierlo, J.V.; Bossche, P. Critical review of state of health estimation methods of Li-ion batteries for real applications. Renew. Sustain. Energy Rev. 2016, 56, 572-587. [CrossRef]

3. Salminen, J.; Kallio, T.; Omar, N.; Gualous, H.; Mierlo, J.V. Chapter 14-Transport Energy-Lithium Ion Batteries. In Future Energy, 2nd ed.; Letcher, T.M., Ed.; Elsevier: Amsterdam, The Netherlands, 2014; pp. 291-309.

4. Andwari, A.M.; Pesiridis, A.; Rajoo, S.; Martinez-Botas, R.; Esfahanian, V. A review of battery electric vehicle technology and readiness levels. Renew. Sustain. Energy Rev. 2017, 78, 414-430. [CrossRef]

5. Corey, G.P. Batteries for stationary standby and for stationary cycling applications part 6: Alternative electricity storage technologies. In Proceedings of the 2003 IEEE Power Engineering Society General Meeting, Toronto, ON, Canada, 13-17 July 2003.

6. Hannan, M.A.; Lipu, M.; Hussain, A.; Mohamed, A. A review of lithium-ion battery state of charge estimation and management system in electric vehicle applications: Challenges recommendations. Renew. Sustain. Energy Rev. 2017, 78, 834-854. [CrossRef] 
7. Akhoundzadeh, M.H.; Panchal, S.; Samadani, E.; Raahemifar, K.; Fowler, M.; Fraser, R. Investigation and simulation of electric train utilizing hydrogen fuel cell and lithium-ion battery. Sustain. Energy Technol. Assess. 2021, 46, 101234.

8. Shang, Y.; Lu, G.; Kang, Y.; Zhou, Z.; Duan, B.; Zhang, C. A multi-fault diagnosis method based on modified sample entropy for lithium-ion battery strings. J. Power Sources 2020, 446, 227275. [CrossRef]

9. Li, X.; Wang, Z.; Zhang, L.; Zou, C.; Dorrell, D.D. State-of-health estimation for li-ion batteries by combing the incremental capacity analysis method with grey relational analysis. J. Power Sources 2019, 410, 106-114. [CrossRef]

10. Garche, J.; Jossen, A. Monitoring and safety tests of batteries: From state of charge (SOC) and health (SOH) to misuse, abuse and crash. In Electrochemical Storage Materials: Supply, Processing, Recycling, and Modeling, Proceedings of the 2nd International Freiberg Conference on Electrochemical Storage Materials, Freiberg, Germany, 11-12 June 2015; AIP Conference Proceedings: Freiberg, Germany, 25 August 2016.

11. Ungurean, L.; Crstoiu, G.; Mihai, V.; Groza, V. Battery state of health estimation: A structured review of models, methods and commercial devices. Int. J. Energy Res. 2016, 41, 151-181. [CrossRef]

12. Yang, S.; Zhang, C.; Jiang, J.; Zhang, W.; Zhang, L.; Wang, Y. Review on state-of-health of lithium-ion batteries: Characterizations, estimations and applications. J. Clean. Prod. 2021, 314, 128015. [CrossRef]

13. Li, Y.; Liu, K.; Aoife, M.F.; Zülke, A.; Berecibar, M.; Nanini-Maury, E.; Van Mierlo, J.; Hoster, H.E. Data-driven health estimation and lifetime prediction of lithium-ion batteries: A review. Renew. Sustain. Energy Rev. 2019, 113, 109254. [CrossRef]

14. Feng, X.; Ouyang, M.; Liu, X.; Lu, L.; Xia, Y.; He, X. Thermal runaway mechanism of lithium ion battery for electric vehicles: A review. Energy Storage Mater. 2018, 10, 246-267. [CrossRef]

15. Tian, J.; Wang, Y.; Chen, Z. Summary of fault diagnosis for lithium battery energy storage system. In Proceedings of the 19th China Conference on System Simulation Technology and Its Application (19th CCSSTA 2018), Guiyang, China, 12 August 2018.

16. Tian, J.; Xiong, R.; Shen, W. A review on state of health estimation for lithium ion batteries in photovoltaic systems. ETransportation 2019, 2, 100028. [CrossRef]

17. Yang, Y.; Okonkwo, E.G.; Huang, G.; Xu, S.; He, Y. On the sustainability of lithium ion battery industry-A review and perspective. Energy Storage Mater. 2021, 36, 186-212. [CrossRef]

18. Qin, D.; Yao, L.; Hu, M. Rapid determination of failure of lithium-ion batteries. World Sci. Technol. Res. Dev. 2012, 34, 21-24.

19. Wang, Z.; Li, J.; Wang, K.; Gao, F.; Tian, B. Analysis of degradation mechanism of lithium iron phosphate/graphite power battery. Rare Met. Cem. Carbide 2020, 48, 63-69.

20. Mei, W.; Zhang, L.; Sun, J.; Wang, Q. Experimental and numerical methods to investigate the overcharge caused lithium plating for lithium ion battery. Energy Storage Mater. 2020, 32, 91-104. [CrossRef]

21. Peled, E.; Menkin, S. Review_SEI: Past, Present and Future. J. Electrochem. Soc. 2017, 164, A1703-A1719. [CrossRef]

22. Jie, L.; Ad Ewuyi, K.; Yagin, N.L.; Landers, R.; Park, J. A Single Particle Model with Chemical/Mechanical Degradation Physics for Lithium Ion Battery State of Health (SOH) Estimation. Appl. Energy 2018, 212, 1178-1190.

23. Shinagawa, C.; Ushiyama, H.; Yamashita, K. Multiscale simulations for lithium-ion batteries: Sei film growth and capacity fading. J. Electrochem. Soc. 2017, 164, A3018-A3024. [CrossRef]

24. Kim, J.; Ma, H.; Cha, H.; Lee, H.; Sung, J.; Seo, M.; Oh, P.; Pak, M.; Cho, J. A highly stabilized nickel-rich cathode material by nanoscale epitaxy control for high-energy lithium-ion batteries. Energy Environ. Sci. 2018, 11, 1449-1459. [CrossRef]

25. Sun, Y.; Zhao, Y.; Wang, J.; Liang, J.; Wang, C.; Sun, Q. A Novel Organic 'Polyurea' Thin Film for Ultralong-Life Lithium-Metal Anodes via Molecular-Layer Deposition. Adv. Mater. 2019, 31, 1806541. [CrossRef] [PubMed]

26. Farmann, A.; Waag, W.; Marongiu, A.; Sauer, D.U. Critical review of on-board capacity estimation techniques for lithium-ion batteries in electric and hybrid electric vehicles. J. Power Sources 2015, 281, 114-130. [CrossRef]

27. Li, R. Study on Evaluation and Estimation Method of Lithium Power Battery Health. Ph.D. Thesis, Harbin University of Science and Technology, Harbin, China, 2016.

28. Li, G.; Lu, H.; Yuan, J.; Li, B. A Review of Lithium-ion Battery Life Research. Chin. J. Power Sources 2016, 40, 1312-1314.

29. Andre, D.; Meiler, M.; Steiner, K.; Wirnmer, C.; Soczka-Guth, T.; Sauer, D.U. Characterization of high-power lithium-ion batteries by electrochemical impedance spectroscopy. experimental investigation. J. Power Sources 2011, 196, 5334-5341. [CrossRef]

30. Tran, N.T.; Khan, A.; Choi, W. State of charge and state of health estimation of agm vrla batteries by employing a dual extended kalman filter and an arx model for online parameter estimation. Energies 2017, 10, 137. [CrossRef]

31. Lotfi, N.; Li, J.; Landers, R.G.; Park, J. Li-ion Battery State of Health Estimation based on an improved Single Particle model. In Proceedings of the American Control Conference IEEE, Seattle, WA, USA, 24-26 May 2017.

32. Tan, C.M.; Singh, P.; Chen, C. Accurate real time on-line estimation of state-of-health and remaining useful life of li ion batteries. Appl. Sci. 2020, 10, 7836. [CrossRef]

33. Lluc, C.C.; Beatriz, A.G. Second-Life Batteries on a Gas Turbine Power Plant to Provide Area Regulation Services. Batteries 2017, 3 , 10.

34. Catton, J.; Walker, S.B.; Mcinnis, P.; Fowler, M.; Gaffney, B. Comparative safety risk and the use of repurposed EV batteries for stationary energy storage. In Proceedings of the 2017 IEEE International Conference on Smart Energy Grid Engineering (SEGE), Oshawa, ON, Canada, 14-17 August 2017.

35. Andre, D.; Nuhic, A.; Soczka-Guth, T.; Sauer, D.U. Comparative study of a structured neural network and an extended kalman filter for state of health determination of lithium-ion batteries in hybrid electricvehicles. Eng. Appl. Artif. Intell. 2013, 26, 951-961. [CrossRef] 
36. Yun, B.; Dong, W.; Wang, D. Online Internal Resistance Measurement Application in Lithium Ion Battery Capacity and State of Charge Estimation. Energies 2018, 11, 1073.

37. Akhil, G.; Liu, Y.; Liang, G. Development of recycling strategy for large stacked systems: Experimental and machine learning approach to form reuse battery packs for secondary applications. J. Clean. Prod. 2020, 275, 124152.

38. Liu, B.; Tang, X.; Gao, F. Joint estimation of battery state-of-charge and state-of-health based on a simplified pseudo-twodimensional model. Electrochim. Acta 2020, 344, 136098. [CrossRef]

39. Kumar, B.; Khare, N.; Chaturvedi, P.K. FPGA-based design of advanced BMS implementing SoC/SoH estimators. Microelectron. Reliab. 2018, 84, 66-74. [CrossRef]

40. Liang, K.; Zhang, Z.; Liu, P.; Wang, Z.; Jiang, S. Data-Driven Ohmic Resistance Estimation of Battery Packs for Electric Vehicles. Energies 2019, 12, 4772. [CrossRef]

41. Wassiliadis, N.; Adermann, J.; Frericks, A.; Pak, M.; Reiter, C.; Lohmann, B. Revisiting the dual extended kalman filter for battery state-of-charge and state-of-health estimation: A use-case life cycle analysis. J. Energy Storage 2018, 19, 73-87. [CrossRef]

42. Guha, A.; Patra, A. State of Health Estimation of Lithium-Ion Batteries Using Capacity Fade and Internal Resistance Growth Models. IEEE Trans. Transp. Electrif. 2018, 4, 135-146. [CrossRef]

43. Ping, S.; Ouyang, M.; Lu, L.; Li, J.; Feng, X. The Co-estimation of State of Charge, State of Health, and State of Function for Lithium-Ion Batteries in Electric Vehicles. IEEE Trans. Veh. Technol. 2017, 67, 92-103.

44. Cacciato, M.; Nobile, G.; Scarcella, G.; Scelba, G. Real-Time Model-Based Estimation of SOC and SOH for Energy Storage Systems IEEE Trans. Power Electron. 2016, 32, 794-803. [CrossRef]

45. Pastor-Fernandez, C.; Uddin, K.; Chouchelamane, G.H.; Widanage, W.D.; Marco, J. Dataset to support: A comparison between electrochemical impedance spectroscopy and incremental capacity-differential voltage as li-ion diagnostic techniques to identify and quantify the effects of degradation modes within battery management systems. J. Power Sources 2017, 360, 301-318. [CrossRef]

46. Howey, D.A.; Mitcheson, P.D.; Yufit, V.; Offer, G.J.; Brandon, N.P. Online measurement of battery impedance using motor controller excitation. IEEE Trans. Veh. Technol. 2014, 63, 2557-2566. [CrossRef]

47. Sabet, P.S.; Stahl, G.; Sauer, D.U. Non-invasive investigation of predominant processes in the impedance spectra of high energy lithium-ion batteries with nickel-cobalt-aluminum cathodes. J. Power Sources 2020, 472, 228189. [CrossRef]

48. Zhang, C.; Li, K.; Deng, J.; Song, S. Improved Realtime State-of-Charge Estimation of LiFePO4 Battery Based on a Novel Thermoelectric Model. IEEE Trans. Ind. Electron. 2017, 64, 654-663. [CrossRef]

49. Tourani, A.; White, P.; Ivey, P. A multi scale multi-dimensional thermo electrochemical modelling of high capacity lithium-ion cells. J. Power Sources 2014, 255, 360-367. [CrossRef]

50. Tian, J.; Xu, R.; Wang, Y.; Chen, Z. Capacity attenuation mechanism modeling and health assessment of lithium-ion batteries. Energy 2021, 221, 119682. [CrossRef]

51. Muratoglu, Y.; Alkaya, A. Unscented kalman filter based state of charge estimation for the equalization of lithium-ion batteries on electrical vehicles. Eng. Technol. Appl. Sci. Res. 2019, 9, 4876-4882. [CrossRef]

52. Farrier, L.; Bucknall, R. Investigating the performance capability of a lithium-ion battery system when powering future pulsed loads. Energies 2020, 13, 1357. [CrossRef]

53. Hossain, M.; Saha, S.; Arif, M.T.; Oo, A.; Haque, E. A Parameter Extraction Method for the Li-Ion Batteries with Wide-Range Temperature Compensation. IEEE Trans. Ind. Appl. 2020, 56, 5625-5636. [CrossRef]

54. Zeng, M.; Zhang, P.; Yang, Y.; Xie, C.; Shi, Y. SOC and SOH Joint Estimation of the Power Batteries Based on Fuzzy Unscented Kalman Filtering Algorithm. Energies 2019, 12, 3122. [CrossRef]

55. Nejad, S.; Gladwin, D.T.; Stone, D.A. A systematic review of lumped-parameter equivalent circuit models for real-time estimation of lithium-ion battery states. J. Power Sources 2016, 316, 183-196. [CrossRef]

56. Zuo, Y.; Hu, X.; Ma, H.; Li, S. Combined State of Charge and State of Health estimation over lithium-ion battery cell cycle lifespan for electric vehicles. J. Power Sources 2015, 273, 793-803.

57. Domenico, D.D.; Fiengo, G.; Stefanopoulou, A. Lithium-Ion Battery State of Charge Estimation with a Kalman Filter Based on an Electrochemical Model. In Proceedings of the 2008 IEEE International Conference on Control Applications, San Antonio, TX, USA, 3-5 September 2008.

58. Wang, Y.; Tian, J.; Sun, Z.; Wang, L.; Chen, Z. A Comprehensive Review of Battery Modeling and State Estimation Approaches for Advanced Battery Management Systems. Renew. Sustain. Energy Rev. 2020, 131, 110015. [CrossRef]

59. Huang, M.; Kumar, M. Electrochemical Model-Based Aging Characterization of Lithium-Ion Battery Cell in Electrified Vehicles. In Proceedings of the ASME 2018 Dynamic Systems and Control Conference 2018, Atlanta, GA, USA, 30 September-3 October 2018.

60. Zhang, Q.; Wang, D.; Yang, B.; Cui, X.; Li, X. Electrochemical model of lithium-ion battery for wide frequency range applications. Electrochim. Acta 2020, 343, 136094. [CrossRef]

61. Lee, J.L.; Chemistruck, A.; Plett, G.L. One-dimensional physics-based reduced-order model of lithium-ion dynamics. J. Power Sources 2012, 220, 430-448. [CrossRef]

62. Jie, G.; Barker, D.; Pecht, M. Prognostics implementation of electronics under vibration loading. Microelectron. Reliab. 2007, 47, 1849-1856.

63. Farmann, A.; Sauer, D.U. Comparative study of reduced order equivalent circuit models for on-board state-of-available-power prediction of lithium-ion batteries in electric vehicles. Appl. Energy 2018, 225, 1102-1122. [CrossRef] 
64. Lai, X.; Wang, S.; Ma, S.; Xie, J.; Zheng, Y. Parameter sensitivity analysis and simplification of equivalent circuit model for the state of charge of lithium-ion batteries-ScienceDirect. Electrochim. Acta 2020, 330, 135239. [CrossRef]

65. Locorotondo, E.; Pugi, L.; Berzi, L.; Pierini, M.; Lutz Em Berger, G. Online Identification of Thevenin Equivalent Circuit Model Parameters and Estimation State of Charge of Lithium-Ion Batteries. In Proceedings of the 2018 IEEE International Conference on Environment and Electrical Engineering and 2018 IEEE Industrial and Commercial Power Systems Europe (EEEIC/I\&CPS Europe), Palermo, Italy, 12-15 June 2018.

66. Wei, H.; Chen, X.; Lü, Z.; Wang, Z.; Chen, L. Online Estimation of Lithium-Ion Battery State of Health Using Grey Neural Network. Power Syst. Technol. 2017, 41, 4038-4044.

67. Panchal, S.; Mcgrory, J.; Kong, J.; Fraser, R.; Fowler, M.; Dincer, I.; Agelin-Chaab, M. Cycling degradation testing and analysis of a lifepo4 battery at actual conditions. Int. J. Energy Res. 2017, 41, 2565-2575. [CrossRef]

68. Liu, X.; Li, W.; Zhou, A. PNGV Equivalent Circuit Model and SOC Estimation Algorithm for Lithium Battery Pack Adopted in AGV Vehicle. IEEE Access 2018, 6, 23639-23647. [CrossRef]

69. He, H.; Xiong, R.; Guo, H.; Li, S. Comparison study on the battery models used for the energy management of batteries in electric vehicles. Energy Convers. Manag. 2012, 64, 113-121. [CrossRef]

70. Barcellona, S.; Piegari, L. Lithium Ion Battery Models and Parameter Identification Techniques. Energies 2017, 10, 2007. [CrossRef]

71. Wang, Y.; Li, M.; Chen, Z. Experimental study of fractional-order models for lithium-ion battery and ultra-capacitor: Modeling, system identification, and validation. Appl. Energy 2020, 278, 115736. [CrossRef]

72. Vepsäläinen, J.; Ritari, A.; Lajunen, A.; Kivekäs, K.; Tammi, K. Energy uncertainty analysis of electric buses. Energies 2018, 11, 3267. [CrossRef]

73. Figueroa-Santos, M.A.; Siegel, J.B.; Stefanopoulou, A.G. Leveraging cell expansion sensing in state of charge estimation: Practical considerations. Energies 2020, 13, 2653. [CrossRef]

74. Deng, Y.; Ying, H.; Jiaqiang, E.; Zhu, H.; Wei, K.; Chen, J. Feature parameter extraction and intelligent estimation of the State-of-Health of lithium-ion batteries. Energy 2019, 176, 91-102. [CrossRef]

75. Severson, K.A.; Attia, P.M.; Jin, N.; Perkins, N.; Jiang, B.; Yang, Z. Data-driven prediction of battery cycle life before capacity degradation. Nat. Energy 2019, 4, 383-391. [CrossRef]

76. Mawonou, S.R.; Eddahech, A.; Dumur, D.; Beauvois, D.; Godoy, E. State-of-health estimators coupled to a random forest approach for lithium-ion battery aging factor ranking-sciencedirect. J. Power Sources 2021, 484, 229154. [CrossRef]

77. Guo, P.; Cheng, Z.; Yang, L. A data-driven remaining capacity estimation approach for lithium-ion batteries based on charging health feature extraction. J. Power Sources 2019, 412, 442-450. [CrossRef]

78. Wang, S.; Han, X.; Chen, L. Particle Filtering for Lithium-ion Battery Residual Life Prediction. Chin. J. Power Sources 2020, 44, $48-53$.

79. Vidal, C.; Malysz, P.; Kollmeyer, P.; Emadi, A. Machine learning applied to electrified vehicle battery state of charge and state of health estimation: State-of-the-art. IEEE Access 2020, 8, 52796-52814. [CrossRef]

80. Klass, V.; Behm, M.; Lindbergh, G. A support vector machine-based state-of-health estimation method for lithium-ion batteries under electric vehicle operation. J. Power Sources 2014, 270, 262-272. [CrossRef]

81. Wei, Z.; Zhao, J.; Ji, D.; Tseng, K.J. A multi-timescale estimator for battery state of charge and capacity dual estimation based on an online identified model. Appl. Energy 2017, 204, 1264-1274. [CrossRef]

82. Vichard, L.; Ravey, A.; Venet, P.; Harel, F.; Hissel, D. A method to estimate battery soh indicators based on vehicle operating data only. Energy 2021, 225, 120235. [CrossRef]

83. Topan, P.A.; Ramadan, M.N.; Fathoni, G.; Cahyadi, A.I.; Wahyunggoro, O. State of Charge (SOC) and State of Health (SOH) estimation on lithium polymer battery via Kalman filter. In Proceedings of the 2016 2nd International Conference on Science and Technology-Computer (ICST), Yogyakarta, Indonesia, 27-28 October 2017.

84. Remmlinger, J.; Buchholz, M.; Soczka-Guth, T.; Dietmayer, K. On-board state-of-health monitoring of lithium-ion batteries using linear parameter-varying models. J. Power Sources 2013, 239, 689-695. [CrossRef]

85. Zhao, P.C.; Qiu, T.W. The Application of UKF Algorithm for 18650-type Lithium Battery SOH Estimation. Appl. Mech. Mater. 2014, 519, 1079-1084.

86. Gholizadeh, M.; Yazdizadeh, A. A Systematic Mixed Adaptive Observer and EKF Approach to Estimate the SOC and SOH of a Lithium-Ion Battery. IET Electr. Syst. Transp. 2019, 10, 135-143. [CrossRef]

87. Fang, L.; Li, J.; Peng, B. Online Estimation and Error Analysis of both SOC and SOH of Lithium-ion Battery based on DEKF Method. Energy Procedia 2019, 158, 3008-3013. [CrossRef]

88. Li, S.; Fang, H.; Shi, B. Remaining useful life estimation of Lithium-ion battery based on interacting multiple model particle filter and support vector regression. Reliab. Eng. Syst. Saf. 2021, 210, 107542. [CrossRef]

89. Qu, J.; Liang, H. Fast Adaptive Tracking Based on Fusion Particle Filter Algorithm. In Proceedings of the 2019 2nd International Conference on Mechanical Engineering, Industrial Materials and Industrial Electronics (MEIMIE 2019), Dalian, China, 29 March 2019.

90. Kim, S.; Park, H.J.; Choi, J.H.; Kwon, D. A novel prognostics approach using shifting kernel particle filter of li-ion batteries under state changes. IEEE Trans. Ind. Electron. 2020, 68, 3485-3493. [CrossRef]

91. Wang, D.; Tsui, K.L. State Space Models Based Prognostic Methods for Remaining Useful Life Prediction of Rechargeable Batteries; Springer: Singapore, 2017; pp. 307-334. 
92. Guha, A.; Patra, A. Particle filtering based estimation of remaining useful life of lithium-ion batteries employing power fading data. In Proceedings of the 2017 IEEE International Conference on Prognostics and Health Management (ICPHM), Dallas, TX, USA, 19-21 June 2017.

93. Zhang, J.; Liu, X.; Chen, C.; Simeone, A. An Intelligent Deformation-Based Approach to the State of Health Estimation of Collided Lithium-Ion Batteries for Facilitating Battery Module Safety Evaluation. Energy Technol. 2020, 8, 2000624. [CrossRef]

94. Fleischer, C.; Waag, W.; Bai, Z.; Sauer, D.U. Adaptive on-line state-of-available-power prediction of lithium-ion batteries. J. Power Electron. 2013, 13, 516-527. [CrossRef]

95. Xia, Z.; Qahouq, J.A. State-of-charge Balancing of Lithium-ion Batteries with State-of-health Awareness Capability. IEEE Trans. Ind. Appl. 2021, 57, 673-684. [CrossRef]

96. Zhang, G.; Patuwo, B.E.; Hu, M.Y. Forecasting with artificial neural networks: The state of the art. Int. J. Forecast. 1998, 14, 35-62. [CrossRef]

97. Naha, A.; Han, S.; Agarwal, S.; Guha, A.; Oh, B. An Incremental Voltage Difference Based Technique for Online State of Health Estimation of Li-ion Batteries. Sci. Rep. 2020, 10, 9526. [CrossRef] [PubMed]

98. Sarmah, S.B.; Kalita, P.; Das, B.; Garg, A.; Sarma, M. Numerical and experimental investigation of state of health of Li-ion battery. Int. J. Green Energy 2020, 17, 510-520. [CrossRef]

99. Bonfitto, A. A Method for the Combined Estimation of Battery State of Charge and State of Health Based on Artificial Neural Networks. Energies 2020, 13, 2548. [CrossRef]

100. Hou, E.; Qiao, X.; Liu, G. Remaining Useful Life Prediction of Power Lithium-Ion Battery based on Artificial Neural Network Model. In Proceedings of the 2017 International Conference on Mechanical, Control and Automation Engineering (MECAE 2017), Wuhan, China, 20 March 2017.

101. Ungurean, L.; Micea, M.V.; Crstoiu, G. Online state of health prediction method for lithium-ion batteries, based on gated recurrent unit neural networks. Int. J. Energy Res. 2020, 44, 6767-6777. [CrossRef]

102. Khumprom, P.; Yodo, N. A Data-Driven Predictive Prognostic Model for Lithium-ion Batteries based on a Deep Learning Algorithm. Energies 2019, 12, 660. [CrossRef]

103. Sterkens, W.; Dillam, D.R.; Goedemé, T.; Dewulf, W.; Jef, R.P. Detection and recognition of batteries on x-ray images of waste electrical and electronic equipment using deep learning-sciencedirect. Resour. Conserv. Recycl. 2021, 168, 105246. [CrossRef]

104. Khan, N.; Ullah, F.; Afnan, U.A.; Baik, S.W. Batteries State of Health Estimation via Efficient Neural Networks with Multiple Channel Charging Profiles. IEEE Access 2020, 9, 7797-7813. [CrossRef]

105. Li, D.; Yang, L. Remaining useful life prediction of lithium battery using convolutional neural network with optimized parameters In Proceedings of the 2020 5th Asia Conference on Power and Electrical Engineering (ACPEE), Chengdu, China, 4-7 June 2020.

106. Fan, Y.; Xiao, F.; Li, C.; Yang, G.; Tang, X. A novel deep learning framework for state of health estimation of lithium-ion battery. J. Energy Storage 2020, 32, 101741. [CrossRef]

107. Zhang, Y.; Xiong, R.; He, H.; Pecht, M. Long Short-Term Memory Recurrent Neural Network for Remaining Useful Life Prediction of Lithium-Ion Batteries. IEEE Trans. Veh. Technol. 2018, 67, 5695-5705. [CrossRef]

108. Ren, L.; Dong, J.; Wang, X.; Meng, Z.; Zhao, L. A data-driven auto-CNN-LSTM prediction model for lithium-ion battery remain useful life. IEEE Trans. Ind. Inform. 2020, 17, 3478-3487. [CrossRef]

109. Tan, T.; Zhao, G. Transfer Learning With Long Short-Term Memory Network for State-of-Health Prediction of Lithium-Ion Batteries. IEEE Trans. Ind. Electron. 2019, 67, 8723-8731. [CrossRef]

110. Klass, V.; Behm, M.; Lindbergh, G. Evaluating Real-Life Performance of Lithium-Ion Battery Packs in Electric Vehicles. J. Electrochem. Soc. 2012, 159, A1856. [CrossRef]

111. Feng, X.; Weng, C.; He, X.; Han, X.; Lu, L.; Ren, D. Online State-of-Health Estimation for Li-Ion Battery Using Partial Charging Segment Based on Support Vector Machine. IEEE Trans. Veh. Technol. 2019, 68, 8583-8592. [CrossRef]

112. Qin, T.; Zeng, S.; Guo, J.; Skaf, Z. A Rest Time-Based Prognostic Framework for State of Health Estimation of Lithium-Ion Batteries with Regeneration Phenomena. Energies 2016, 9, 896. [CrossRef]

113. Nuhic, A.; Terzimehic, T.; Soczka-Guth, T.; Buchholz, M.; Dietmayer, K. Health diagnosis and remaining useful life prognostics of lithium-ion batteries using data-driven methods. J. Power Sources 2013, 239, 680-688. [CrossRef]

114. Song, Z.; Gao, J.; Pan, L.; Xi, J. Lithium-ion battery health status prediction based on principal component analysis and improved support vector machine. Automot. Technol. 2020, 11, 21-27.

115. Widodoa, A.; Shim, M.; Caesarendra, W.; Yang, B. Intelligent prognostics for battery health monitoring based on sample entropy. Expert Syst. Appl. 2011, 38, 11763-11769. [CrossRef]

116. Zhang, J.; Lee, J. A review on prognostics and health monitoring of Li-ion battery. J. Power Sources 2011, 195, 6007-6014. [CrossRef]

117. Zhang, C.; He, Y.; Yuan, L.; Xiang, S.; Wang, J. Prognostics of Lithium-Ion Batteries Based on Wavelet Denoising and DE-RVM. Comput. Intell. Neurosci. 2015, 2015, 918305. [CrossRef]

118. Liu, D.; Zhou, J.; Pan, D.; Peng, Y.; Peng, X. Lithium-ion battery remaining useful life estimation with an optimized Relevance Vector Machine algorithm with incremental learning. Measurement 2015, 63, 143-151. [CrossRef]

119. Guo, R.; Liu, Z.; Wei, Y. Remaining useful life prediction for the air turbine starter based on empirical mode decomposition and relevance vector machine. Trans. Inst. Meas. Control 2020, 42, 2578-2588. [CrossRef]

120. Hao, D. Life Prediction of Satellite Key Components Based on RVM-PF. Ph.D. Thesis, National University of Defense Technology, Changsha, China, 2011. 
121. Qin, X.; Qi, Z.; Zhao, H.; Feng, W.; Guan, X. Prognostics of remaining useful life for lithium-ion batteries based on a feature vector selection and relevance vector machine approach. In Proceedings of the IEEE International Conference on Prognostics \& Health Management IEEE, Dallas, TX, USA, 19-21 June 2017.

122. Shen, S.; Sadoughi, M.; Chen, X.; Hong, M.; Hu, C. A deep learning method for online capacity estimation of lithium-ion batteries. J. Energy Storage 2019, 25, 100817. [CrossRef]

123. Zhao, L.; Wang, Y.; Cheng, J. A Hybrid Method for Remaining Useful Life Estimation of Lithium-Ion Battery with Regeneration Phenomena. Appl. Sci. 2019, 9, 1890. [CrossRef]

124. Dong, W.; Qiang, M.; Pecht, M. Prognostics of lithium-ion batteries based on relevance vectors and a conditional three-parameter capacity degradation model. J. Power Sources 2013, 239, 253-264.

125. Zhou, J. A Method for Predicting the Residual Life of Lithium-Ion Batteries Based on RVM. Ph.D. Thesis, Harbin Institute of Technology, Harbin, China, 2013.

126. Zhang, Z.; Huang, M.; Chen, Y.; Zhu, S. Prediction of Lithium-ion Battery's Remaining Useful Life Based on Relevance Vector Machine. SAE Int. J. Altern. Powertrains 2016, 5, 30-40. [CrossRef]

127. Liu, T.; Sun, Q.; Feng, J.; Pan, Z.; Huangpeng, Q. Residual life estimation under time-varying conditions based on a Wiener process. J. Stat. Comput. Simul. 2017, 87, 211-226. [CrossRef]

128. Jin, G.; David, E.M.; Zhou, Z. A Bayesian framework for on-line degradation assessment and residual life prediction of secondary batteries inspacecraft. Reliab. Eng. Syst. Saf. 2013, 113, 7-20. [CrossRef]

129. Feng, J.; Kvam, P.; Tang, Y. Remaining useful lifetime prediction based on the damage-marker bivariate degradation model: A case study on lithium-ion batteries used in electric vehicles. Eng. Fail. Anal. 2016, 70, 323-342. [CrossRef]

130. Zhai, Q.; Ye, Y. RUL Prediction of Deteriorating Products Using an Adaptive Wiener Process Model. IEEE Trans. Ind. Inform. 2017, 13, 2911-2921. [CrossRef]

131. Xu, X.; Yu, C.; Tang, S.; Sun, X.; Wu, L. State-of-Health Estimation for Lithium-ion Batteries Based on Wiener Process with Modeling the Relaxation Effect. IEEE Access 2019, 7, 105186-105201. [CrossRef]

132. Hartikainen, J.; Särkkä, S. Kalman filtering and smoothing solutions to temporal Gaussian process regression models. In Proceedings of the IEEE International Workshop on Machine Learning for Signal Processing, Kittila, Finland, 29 August-1 September 2010.

133. Yang, D.; Zhang, X.; Pan, R.; Wang, Y.; Chen, Z. A novel Gaussian process regression model for state-of-health estimation of lithium-ion battery using charging curve. J. Power Sources 2018, 384, 387-395. [CrossRef]

134. He, Y.; Shen, J.; Shen, J.; Ma, Z. State of health estimation of lithium-ion batteries: A multiscale Gaussian process regression modeling approach. AIChE J. 2015, 61, 1589-1600. [CrossRef]

135. Lu, M. Research on Power Battery SOH Estimation and Fault Prediction Method. Master's Thesis, Beijing University of Technology, Beijing, China, 2015.

136. Richardson, R.R.; Osborne, M.A.; Howey, D.A. Gaussian process regression for forecasting battery state of health. J. Power Sources 2017, 357, 209-219. [CrossRef]

137. Liu, D.; Pang, J.; Zhou, J.; Yu, P.; Pecht, M. Prognostics for state of health estimation of lithium-ion batteries based on combination Gaussian process functional regression. Microelectron. Reliab. 2013, 53, 832-839. [CrossRef]

138. Fan, T.; Wei, Z. Ensemble of model-based and data-driven prognostic approaches for reliability prediction. In Proceedings of the 2017 Prognostics and System Health Management Conference (PHM-Harbin), Harbin, China, 9-12 July 2017.

139. Eddahech, A.; Briat, O.; Bertrand, N.; Delétage, J.Y.; Vinassa, J.M. Behavior and State-of-Health Monitoring of Li-ion Batteries Using Impedance Spectroscopy and Recurrent Neural Networks. Int. J. Electr. Power Energy Syst. 2012, 42, 487-494. [CrossRef]

140. Zhang, H. A New Method for Estimating the SOH of Lithium Batteries Based on IMM. Master's Thesis, Hefei University of Technology, Hefei, China, 2019.

141. Wei, J.; Dong, G.; Chen, Z. Remaining Useful Life Prediction and State of Health Diagnosis for Lithium-Ion Batteries Using Particle Filter and Support Vector Regression. IEEE Trans. Ind. Electron. 2018, 65, 5634-5643. [CrossRef]

142. Wang, Z.; Ma, J.; Zhang, L. State-of-Health Estimation for Lithium-Ion Batteries Based on the Multi-Island Genetic Algorithm and the Gaussian Process Regression. IEEE Access 2017, 5, 21286-21295. [CrossRef]

143. Zhang, X.; Wang, Y.; Liu, C.; Chen, Z. A novel approach of battery pack state of health estimation using artificial intelligence optimization algorithm. J. Power Sources 2018, 376, 191-199. [CrossRef]

144. Li, L. A Novel Online Parameter Identification Algorithm for Fractional-Order Equivalent Circuit Model of Lithium-Ion Batteries. Int. J. Electrochem. Sci. 2020, 15, 6863-6879. [CrossRef]

145. Andre, D.; Appel, C.; Soczka-Guth, T.; Sauer, D.U. Advanced mathematical methods of SOC and SOH estimation for lithium-ion batteries. J. Power Sources 2013, 225, 20-27. [CrossRef]

146. Tang, X.; Zou, C.; Yao, K.; Chen, G.; Liu, B.; He, Z.; Gao, F. A fast estimation algorithm for lithium-ion battery state of health. J. Power Sources 2018, 396, 453-458. [CrossRef]

147. Chang, Y.; Fang, H. A hybrid prognostic method for system degradation based on particle filter and relevance vector machine. Reliab. Eng. Syst. Saf. 2019, 186, 51-63. [CrossRef]

148. Hong, S.; Yue, T.; Liu, H. Vehicle energy system active defense: A health assessment of lithium-ion batteries. Int. J. Intell. Syst. 2020, 1, 1-19. [CrossRef] 
149. Yun, Z.; Qin, W.; Shi, W.; Ping, P. State-of-Health Prediction for Lithium-Ion Batteries Based on a Novel Hybrid Approach. Energies 2020, 13, 4858. [CrossRef]

150. Krawczyk, B.; Minku, L.L.; Gama, J.; Stefanowski, J.; Woniak, M. Ensemble learning for data stream analysis: A survey. Inf. Fusion 2017, 37, 132-156. [CrossRef]

151. Sagi, O.; Rokach, L. Ensemble learning: A survey. Wiley Interdiscip. Rev. Data Min. Knowl. Discov. 2018, 8, e1249. [CrossRef]

152. Gomes, H.M.; Barddal, J.P.; Enembreck, F.; Bifet, A. A Survey on Ensemble Learning for Data Stream Classification. ACM Comput. Surv. 2017, 50, 1-36. [CrossRef]

153. Ma, C.; Zhai, X.; Wang, Z.; Tian, M.; Yu, Q.; Liu, L. State of health prediction for lithium-ion batteries using multiple- view feature fusion and support vector regression ensemble. Int. J. Mach. Learn. Cybern. 2019, 10, 2269-2282. [CrossRef]

154. Li, Y.; Zou, C.; Berecibar, M.; Nanini-Maury, E.; Chan, C.W.; Peter, V. Random forest regression for online capacity estimation of lithium-ion batteries. Appl. Energy 2018, 232, 197-210. [CrossRef]

155. Chen, Z. On-Board State of Health Estimation for Lithium-ion Battery Using Random Forest. In Proceedings of the 2018 IEEE International Conference on Industrial Technology (ICIT), Lyon, France, 20-22 February 2018. 